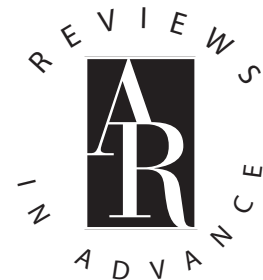

Review in Advance first posted online on January 20, 2014. (Changes may still occur before final publication online and in print.)

\title{
Antecedents of Personality Disorder in Childhood and Adolescence: Toward an Integrative Developmental Model
}

\section{Filip De Fruyt and Barbara De Clercq}

Department of Developmental, Personality and Social Psychology, Ghent University, B-9000 Ghent, Belgium; email: Filip.DeFruyt@ugent.be, BarbaraJ.DeClercq@ugent.be

Annu. Rev. Clin. Psychol. 2014. 10:27.1-27.28

The Annual Review of Clinical Psychology is online at http://clinpsy.annualreviews.org

This article's doi:

10.1146/annurev-clinpsy-032813-153634

Copyright (C) 2014 by Annual Reviews. All rights reserved

\section{Keywords}

developmental antecedents, personality disorders, personality pathology, FFM, DSM-5, psychopathology assessment

\begin{abstract}
Antecedents of personality disorder in childhood and adolescence have been a neglected area in official taxonomies of mental disorders such as the International Classification of Diseases or the different editions of the Diagnostic and Statistical Manual of Mental Disorders. An evolving research field, however, underscores the importance of antecedents for understanding psychopathology and personality pathology in adulthood. The current article summarizes the history, updates reviews, and incorporates new research findings into an integrative scheme for conceptualizing personality pathology in childhood and adolescence. Implications of this model for assessment, future research, and intervention are discussed.
\end{abstract}




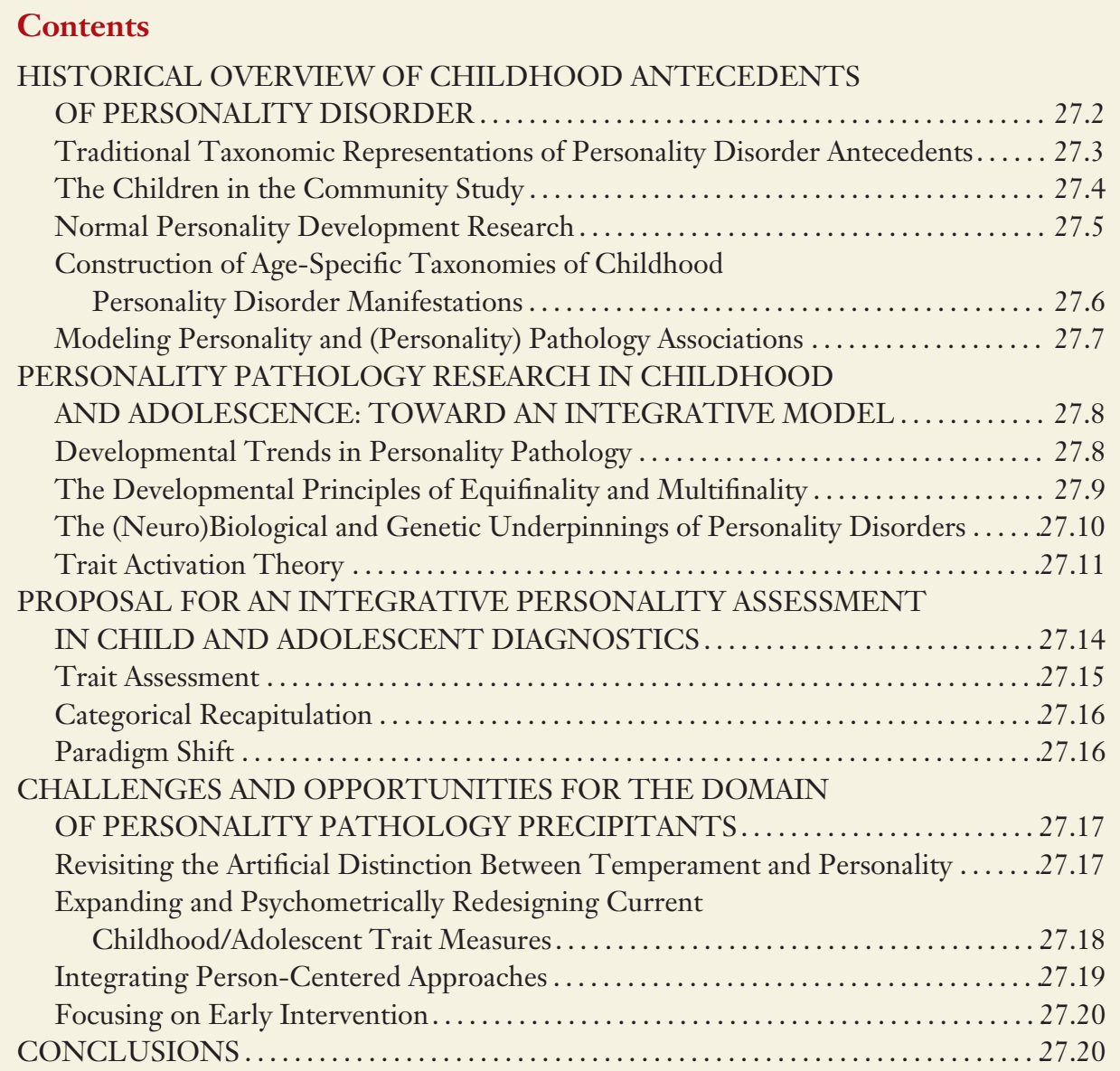

\section{HISTORICAL OVERVIEW OF CHILDHOOD ANTECEDENTS OF PERSONALITY DISORDER}

The two major taxonomies that classify mental disorders, i.e., the tenth edition of the International Statistical Classification of Diseases and Related Disorders [ICD-10; World Health Organ. (WHO) 1994] and the fifth edition of the Diagnostic and Statistical Manual of Mental Disorders [DSM-5; Am. Psychiatr. Assoc. (APA) 2013, p. 645], allow the diagnosis of a personality disorder (PD) from young adulthood onward. A PD is defined in ICD-10 (WHO 1994, p. 157) as: “. . . a severe disturbance in the characteriological constitution and behavioral tendencies of the individual, usually involving several areas of the personality, and nearly always associated with considerable personal and social disruption." The DSM system (APA 2013, p. 645) describes a PD as "an enduring pattern of inner experience and behavior that deviates markedly from the expectations of the individual's culture, is pervasive and inflexible, has on onset in adolescence or early adulthood, is stable over time, and leads to distress or impairment."

Although both systems were developed by independent organizations, their descriptions for most PDs are strikingly similar at the conceptual level. Most relevant for the current review,

De Fruyt • De Clercq 
however, is the fact that both systems have little to say about the nature and significance of PD precursors in childhood or adolescence (De Clercq \& De Fruyt 2012, Widiger et al. 2009), although they explicitly acknowledge that PDs do not appear out of the blue in emerging adulthood. The present review starts from this historical taxonomic neglect of PD antecedents and further evaluates the current status of the PD precursor research field, highlighting a number of major contributions from various empirical sources that have instigated many personality researchers to disclose the nature and etiology of adult PDs.

\section{Traditional Taxonomic Representations of Personality Disorder Antecedents}

ICD-10 (WHO 2010) includes a separate chapter V dealing with the "Mental and Behavioral Disorders" and groups the PDs in a distinct section entitled "Disorders of Adult Personality and Behavior." Almost parallel to this, DSM-5 (APA 2013) distinguishes within its section II ten PDs, i.e., the paranoid, schizoid, schizotypal, antisocial, borderline, histrionic, narcissistic, avoidant, dependent, and obsessive-compulsive PDs, supplemented by “other personality disorders," including personality change due to another medical condition, and other specified PD and unspecified PD. Both taxonomies largely agree upon the conceptualization of PDs as categorical constructs but slightly differ in the labels that are used to denote PDs (e.g., anankastic PD in ICD-10 versus obsessive-compulsive PD in DSM-5). Also, the PD condition of schizotypy is not described in the ICD PD section but rather is assigned to the schizophrenia section.

Although both systems include several chapters listing a broad set of mental disorders in childhood and adolescence, specific precipitants of PDs are not formally considered, except for some vague symptoms listed in the "Development and Course" sections, such as solitariness, poor relationships, social anxiety, underachieving at school, and peculiar thoughts and language, that may be apparent during the childhood and adolescence of patients who develop the paranoid, schizoid, and schizotypal PDs later on. These precipitant conditions, however, are aspecific and are not considered in the diagnostic criteria sets for particular PDs (APA 2013). The only exception to this is the diagnosis of conduct disorder that is defined as a necessary preceding condition for the dissocial (ICD) or antisocial (DSM-5) PD. In both systems, this PD is the only PD for which an explicit age restriction is defined. The introductory text of the PD section in ICD-10 does state that PDs are “ ... developmental conditions, which appear in childhood or adolescence and continue into adulthood" (WHO 2010, p. 156), though it concludes that it is highly unlikely that a PD will be diagnosed before the age of 16 or 17 years. Likewise, DSM-5 states that PD features may become manifest during adolescence and that if symptoms are already present in childhood, they " ... will often not persist unchanged into adult life" (APA 2013, p. 647). A PD diagnosis is then considered only in those "relatively unusual instances in which the individual's particular maladaptive personality traits appear to be pervasive, persistent, and unlikely to be limited to a particular developmental stage or another mental disorder" (APA 2013, p. 647). If a PD diagnosis in childhood/ adolescence is considered, then symptoms must have been apparent for at least one year (APA 2013).

Historically, however, DSM-III (APA 1980) did distinguish an avoidant, a schizoid, an identity, and an oppositional disorder considered to be either early manifestations of the avoidant, schizoid, borderline, and passive-aggressive PDs, respectively, or to show continuity with these conditions (Widiger et al. 2009). However, these references were either dropped (schizoid and identity disorders), referred to the DSM appendix (the passive aggressive PD; APA 1994), or subsumed by other conditions (such as the avoidant disorder in childhood that was incorporated in the social phobia diagnosis) in DSM-IV (APA 1994).

In addition, both ICD-10 and the DSM-5 include among their diagnostic entities several childhood conditions that represent trait-like characteristics as one of their defining features,

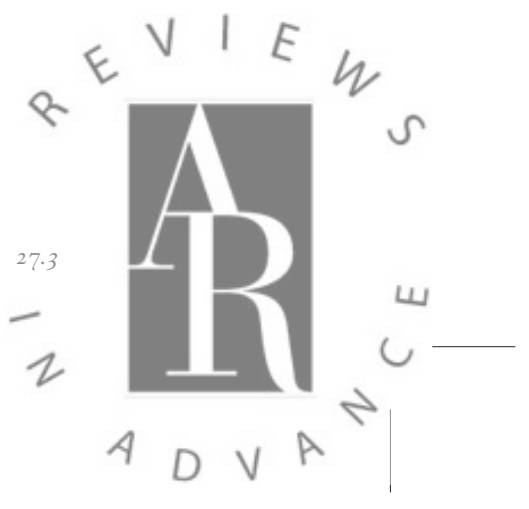


such as for example attention deficit and hyperactivity disorder (ADHD). Parallel to PDs, these diagnostic entities have an enduring character with impairing impact for the child/adolescent and/or his/her family and interpersonal and school environments. These phenomena, however, are not formally listed as a PD in the respective sections of ICD-10 or DSM-5.

De Clercq \& De Fruyt (2012) discussed a number of such diagnoses observable in childhood and adolescence that qualify for these criteria, including the frequently debated ADHD diagnosis from the DSM-5 category of "Neurodevelopmental Disorders" and the DSM-5 anxiety disorder "social anxiety disorder/social phobia." Although ADHD cannot be directly tied to a DSM-5 PD, it is primarily a personality-based disorder (Martel et al. 2010) characterized by the traits of inattentiveness, poor impulse control, and a lack of persistence. Evidence from a recent prospective study has in addition demonstrated that childhood ADHD symptoms uniquely predict later borderline personality pathology (Stepp et al. 2012a), perhaps reflecting their interconnectedness at a certain latent trait level.

Symptoms of social anxiety disorder/social phobia, on the contrary, can be directly linked to indicators of the avoidant PD, whereas more dissocial disorders, such as Asperger syndrome, have features in common with the schizoid PD (Cohen et al. 2005). The latter examples suggest that these pathologies probably reflect a single-spectrum disorder instead of representing separate diagnostic entities that are taxonomically classified in different ICD-10 chapter sections or DSM-5 categories (Cohen et al. 2005, Rettew 2000). De Clercq \& De Fruyt (2012) therefore argued that new taxonomic conceptualizations of personality pathology (Clark 2007, Widiger \& Clark 2000) should be able to describe such maladaptive trait patterns at different developmental phases, but not by inventing new categorical concepts or by expanding the number of PDs, but rather by exploring alternative conceptualizations of personality pathology.

From hindsight, the reservations of ICD-10 and the different DSM editions to make formal diagnoses of PDs before adult age are understandable given the legitimate concern regarding the use of diagnostic labels for denoting mental disorders that have a stigmatizing character, at an age when personality is thought to be "under construction." It can further be argued that diagnosing a (personality) disorder in developmentally sensitive periods such as adolescence is generally more difficult because one has to differentiate symptoms indicative of (personality) pathology from transient expressions of normative (personality) trends at an age stage that is known for a lot of turmoil (De Fruyt \& De Clercq 2012). For emotional disorders, for example, ICD-10 explicitly states that "... many emotional disorders in childhood seem to constitute exaggerations of normal developmental trends rather than phenomena that are qualitatively abnormal in themselves" (WHO 2010, p. 214). In the context of considering borderline PD in adolescence (Chanen \& Kaess 2012), for example, this implies that assessment practitioners will face the difficult task of differentiating transient symptoms as an expression of normative development from those indicative of a latent emotional instability. Finally, early personality pathology precipitants were historically not considered because of a lack of coherent knowledge on antecedent conditions and their significance for understanding PDs exhibited in adulthood (Cohen 2008, Widiger et al. 2009a), hindering the further elaboration of PD antecedents in the leading diagnostic taxonomies.

\section{The Children in the Community Study}

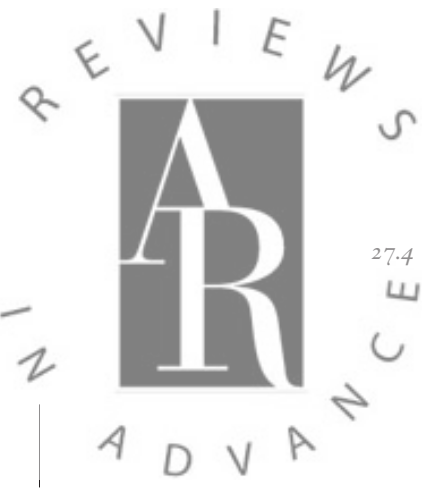

The Children in the Community Study (CIC; Cohen \& Cohen 1996) has been a landmark project for the exploration of developmental antecedents of personality pathology (Cohen \& Crawford 2005, Cohen et al. 2005) in terms of identifying risk factors for later personality pathology and the assessment of the predromal signs in childhood. The study was originally started by Kogan et al. (1977) to examine the need for social services in mothers of a random sample of 1 - to 10-year-old

De Fruyt • De Clercq 
children in two New York counties. Cohen and colleagues conducted a first follow-up in 1983 and expanded the scope to the assessment of early Axis I psychopathology by administering the Diagnostic Interview Schedule for Children (Costello et al. 1984) to adolescents and their mothers. They also assessed a series of contextual variables (Cohen et al. 2005). The second follow-up, when participants were in their mid-adolescence, covered a description of DSM-III-R (APA 1987) PD criteria modeled after an initial version of the Structured Clinical Interview for DSM-III-R PDs (Spitzer \& Williams 1986). Additional follow-up assessments were conducted, aligning the assessment indicators with the new diagnostic criteria of DSM-IV (APA 1994) PDs. At the age of 33, participants were clinically assessed with the Structural Clinical Interview for DSM-IV disorders (First et al. 1997). The CIC study did show some weaknesses, given the difficulties to select age-appropriate indicators of personality pathology, to make these sets of indicators comparable across time, and to align these indicators with the different DSM editions and diagnostic criteria. Nevertheless, the achievements and contributions of the CIC study were major, describing a series of results and key principles that have substantially contributed to our understanding of developmental personality pathology.

The innovative findings of the CIC study stimulated the research area of PD precursors, with a first phase of research that focused on PD constructs in childhood and adolescence that were primarily defined for adults, sometimes after slight modifications to adapt the items to the behavior exhibited by the age groups under consideration. An overview of the DSM-related measures that have been used to assess personality pathology in younger age groups is provided by Shiner (2007), whereas Tackett et al. (2009) and De Fruyt \& De Clercq $(2012,2013)$ have provided comprehensive overviews of the studies that adopted either comprehensive measures or examined specific PDs in preadulthood. These reviews are complemented by two excellent special journal issues on this subject compiled by Development and Psychopathology (Cicchetti \& Crick 2009) and the Fournal of Psychopathology and Behavioral Assessment (Tackett 2010).

\section{Normal Personality Development Research}

An important research line that has indirectly contributed to the emerging area of personality pathology antecedents is work done in the domain of normal child and adolescent personality development. Digman and colleagues (1963) were the first to show that the Big Five dimensions of extraversion, agreeableness, conscientiousness, neuroticism/emotional stability, and intellect (Goldberg 1990) were also evident in teacher ratings of children ages 4 to 12. Building upon this seminal work, Kohnstamm et al. (1998) confirmed that these five dimensions also served as an adequate framework to accommodate parental free descriptions of children's personality. Mervielde \& De Fruyt (1999) and Halverson et al. (2003) subsequently represented the content enclosed in free descriptor sets that were compiled in Belgium and the United States, respectively, into the Hierarchical Personality Inventory for Children (HiPIC; Mervielde \& De Fruyt 1999, Mervielde et al. 2009) and the Inventory of Children's Individual Differences (ICID; Halverson et al. 2003).

The HiPIC assesses five major factors, i.e., emotional stability, extraversion, imagination, benevolence, and conscientiousness, to account for the specific nature of the content enclosed in free descriptions, whereas identical labels as specified for the five-factor model (FFM) were used to label the ICID domains. Both inventories further identified a number of lower-order facets that structured the content of the parental free descriptions. Tackett et al. (2014a) examined the relationships between these two inventories in a community sample of Ontarian youths ages 6 to 18 and showed convergent correlations across the FFM dimensions ranging from 0.56 (neuroticism) to 0.87 (conscientiousness), uncorrected for unreliability. Parallel to findings in

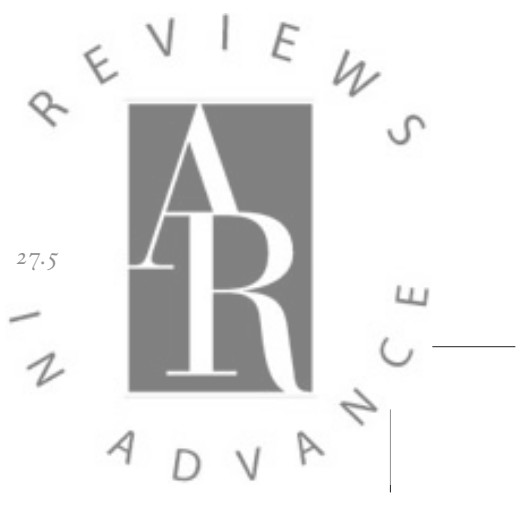


adults, considerable rank-order stability of FFM traits has been observed in adolescence, in both general (De Fruyt et al. 2006) and clinical (De Bolle et al. 2009) samples, with specific normative change patterns described for adolescent boys and girls (McCrae et al. 2002).

John and colleagues (1994) further explored the nomological network of the FFM [derived from California Child Q-sort ratings (Block \& Block 1980)] in adolescent personality, highlighting the FFM's potential to advance our understanding of broad dimensions of psychopathology such as internalizing and externalizing behavior assessed with the Child Behavior Checklist (Achenbach 1991). Neuroticism (positively) and conscientiousness (negatively) turned out to be associated with internalizing problems, whereas externalizing behavior was related to low agreeableness and conscientiousness as well as to high extraversion. Parallel findings were obtained by Van Leeuwen and colleagues (2004a) based upon HiPIC and Child Behavior Checklist relations, and by Tackett et al. (2014a), who inspected HiPIC/ICID-short version (S) (Deal et al. 2007) and Child Behavior Checklist associations. The HiPIC dimensions significantly outperformed those of the ICID-S in terms of explaining variance in both internalizing ( $52 \%$ for the HiPIC versus $35 \%$ captured by the ICID-S) and externalizing (59\% versus 46\%) pathology.

The evidence on the validity of the FFM in younger age groups as well as the fact that the FFM was demonstrated to be a useful model for describing personality pathology in adulthood (Samuel \& Widiger 2008, Saulsman \& Page 2004, Widiger \& Mullins-Sweatt 2009, Widiger et al. 2002) inspired researchers to examine the relationships between the FFM and PD measures in adolescence. De Clercq \& De Fruyt (2003) and De Clercq et al. (2004) administered either the authorized Dutch/Flemish translation of the revised Neuroticism-Extroversion-Openness Personality Inventory-Revised (NEO-PI-R) (Costa \& McCrae 1992, Hoekstra et al. 1996) or the HiPIC (Mervielde \& De Fruyt 1999), together with the Assessment of DSM-IV Personality Disorders questionnaire (ADP-IV; Schotte et al. 2004), to two independent groups of adolescents. Strong parallels were observed between adulthood and adolescence at the FFM domain level, with a convergent pattern of positive correlations with neuroticism and a consistently negative pattern of associations with the remaining FFM dimensions [see also De Fruyt \& De Clercq (2013) and De Clercq \& De Fruyt (2012) for extensive reviews]. Meanwhile, Tromp \& Koot (2009) have provided additional confirmation for parallel associations between alternative dimensional representations of PDs, operationalized by the Dimensional Assessment of Personality Pathology-Basic Questionnaire (DAPP-BQ; Livesley 1990) and DSM-IV PDs. Together, these studies point to similar associations between general and maladaptive traits from adolescence to adulthood, underscoring the significance of conceptualizing a life-span perspective on PDs within one overarching structural framework.

\section{Construction of Age-Specific Taxonomies of Childhood Personality Disorder Manifestations}

The studies on normal personality structure in childhood and the evidence on the relations of childhood FFM traits with PD measures have introduced a new perspective on how to define the domain of personality pathology, moving researchers to start a bottom-up investigation on the structure of maladaptive traits in childhood and adolescence. This approach is the reverse of the exclusive top-down applications that imported adult PD measures for use in adolescents (e.g., DAPP-BQ-A; Tromp \& Koot 2008) and has created a new avenue for exploring whether age-specific operationalizations of personality pathology result in a divergent underlying trait structure.

Following such a bottom-up strategy, De Clercq et al. (2006) started with the compilation of a set of maladaptive indicators of personality pathology notable in childhood and adolescence,

De Fruyt • De Clercq 
including maladaptively formulated variants of the lexically based HiPIC items. ${ }^{1}$ The adoption of a top-down strategy further complemented this set of indicators by adding items from adult personality pathology instruments that were judged applicable in adolescence. The resulting set of 172 items was administered to parents of children and adolescents from the general population and a clinical sample. The variance turned out to be best represented by a four-dimensional structure, including emotional instability, introversion, disagreeableness, and compulsivity factors, that explained $48 \%$ of the variance. Both the number and the nature of these factors closely resembled dimensional models of personality pathology defined for adults, such as the three-dimensional Schedule for Nonadaptive and Adaptive Personality (SNAP; Clark 1993), which includes the positive and negative emotionality and constraint dimensions, and the DAPP-BQ (Livesley 1990), which includes emotional instability, introversion, disagreeableness, and compulsivity. De Clercq et al. (2006) further examined the lower-order structure of personality pathology in childhood and adolescence and compiled the Dimensional Personality Symptom Item (DIPSI) pool, assessing the previous main factors and 27 specific personality facets. In addition, they constructed a marker set of traits for research purposes that includes three core facets per domain.

The availability of a measure specifically designed to assess maladaptive traits in childhood and adolescence generated a number of studies that underscore the importance of considering a trait perspective when studying psychopathology at younger ages and PD precipitants in particular. For example, De Clercq et al. (2010) demonstrated how specific DIPSI facets may help to characterize dimensions of autism symptoms in a sample of 194 children ages 6 to 14 years with a formal DSMIV diagnosis of autism or Asperger syndrome or pervasive developmental disorder-not otherwise specified. Aelterman et al. (2010) showed how the DIPSI explained variance beyond general trait operationalizations in obsessive-compulsive PD in adolescence.

\section{Modeling Personality and (Personality) Pathology Associations}

Considerable progress has been made in the conceptualization and modeling of the relationships between personality and broad dimensions of psychopathology (De Bolle et al. 2012, Krueger 2005), such as internalizing and externalizing pathology as assessed by the Child Behavior Checklist (Achenbach 1991). To the extent that personality problems are (partly) covered by these broad descriptive dimensions, such models may also advance our understanding of developmental antecedents of PDs. Different views exist on how personality and different forms of psychopathology may relate (De Bolle et al. 2012).

First, the vulnerability model assumes that individuals have one or more traits that increase the probability of developing later psychopathology. For example, trait neuroticism is a well-known vulnerability factor for developing later depression. Likewise, neuroticism may be considered a liability for manifesting borderline PD symptoms in adulthood (Skodol et al. 2002).

The pathoplasty/exacerbation model assumes that the course and manifestation of (personality) pathology is affected by general trait variance, where both pathology and general traits may have a different origin and/or emerge at different moments in development. For example, the expression of borderline traits may be affected by the individual's standing on the interpersonal dimensions of extraversion and agreeableness.

The pathoplasty model contrasts with the complication/scar model, describing lasting effects of psychopathology on traits. For example, panic attacks and phobias in adolescence may undermine

\footnotetext{
${ }^{1}$ Maladaptive items of the HiPIC imagination factor were not written because it was judged to be difficult to transform imagination items into maladaptive variants.
}

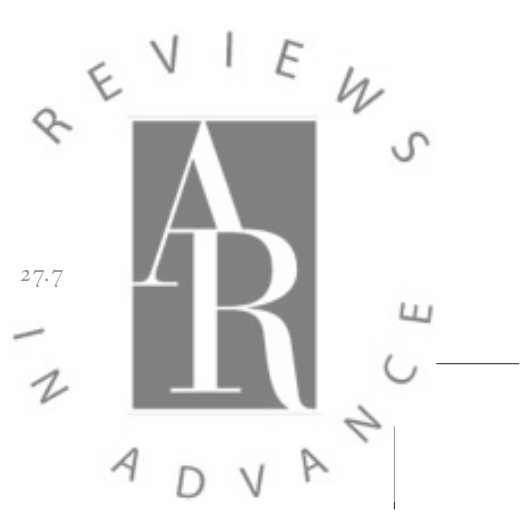


and affect adolescents' self-confidence scores, contributing to neuroticism. Evidence for such reciprocal effects of personality on personality pathology (pathoplasty) and vice versa (complication/scar) has been described in longitudinal studies on PDs in adulthood (Warner et al. 2004), but similar influences may exist in preadulthood (see also our conceptual model described below).

Finally, traits and personality pathology may form continua, where general and maladaptive traits form a spectrum due to shared underlying factors, with a higher probability of dysfunction manifestations at the extremes of the trait dimensions. For example, very high scores on the conscientiousness dimension may be manifested in features of the obsessive-compulsive PD, whereas elevated agreeableness scores may be indicative of dependent personality pathology. In a sample of 1,569 twin pairs ages 9 to 17, Tackett et al. (2014b) showed that variance in negative emotionality, assessed with the Child and Adolescents Dispositions Scales (Lahey et al. 2008), overlapped substantially at both the phenotypic and etiologic levels with a general factor of psychopathology, underscoring the concept of a spectrum between a broad personality factor and a psychopathology factor. The idea of a broad general factor of psychopathology has gained importance as a means to model psychopathology co-occurrence across development (Lahey et al. 2011), including the representation of personality pathology in adulthood (Trull et al. 2013). At the operational level, however, the spectrum model is difficult to distinguish from the continuity model, which refers to phenotypic covariation between traits and personality pathology within and across time without making assumptions on the nature and etiology of this covariation. Although there is no consensus on the preferred model for an optimal understanding of trait-psychopathology relationships, all models have contributed to unraveling the complex association of traits and pathology.

\section{PERSONALITY PATHOLOGY RESEARCH IN CHILDHOOD AND ADOLESCENCE: TOWARD AN INTEGRATIVE MODEL}

A number of recently published reviews discuss developmental antecedents of personality pathology (De Clercq \& De Fruyt 2012; De Fruyt \& De Clercq 2012, 2013; Shiner 2009; Tackett et al. 2009; Widiger et al. 2009). Building upon these reviews and additional recent evidence, in this second section we discuss four key points that are relevant for a comprehensive understanding of personality pathology antecedents and pathways to PDs in adulthood: (a) developmental trends in personality pathology; (b) the significance of the equifinality and multifinality principles (Cicchetti \& Rogosch 1996); (c) the (neuro)biological and genetic underpinnings of personality pathology, including gene-environment interactions and correlations; and finally $(d)$ trait-activation theory (Tett \& Burnett 2003). We integrate these key points into a dynamic explanatory trait-based model of emerging personality pathology. This conceptual model incorporates the previously described etiological models on trait-psychopathology relationships and is further helpful in charting a fourstep assessment process of personality pathology. The model also facilitates the use of different informants to describe both the nature and the severity of personality symptoms and identifies areas of intervention to prevent trait manifestations from developing into maladaptive patterns.

\section{Developmental Trends in Personality Pathology}

The CIC researchers described a number of developmental trends, showing that the highest prevalence rates of PD symptoms were during early adolescence, followed by linear declines until the age of 29 (Johnson et al. 2000); these declines continued until the age of 38 for histrionic and narcissistic symptoms. Johnson et al. (2000) framed these findings as normative declines in impulsivity, attention seeking, and dependency in association with greater maturity and self-control. Beyond these normative declines, however, Johnson et al. (2000) also found individual variability, with $21 \%$ of the participants in the CIC study showing increases in PD symptoms. Parallel to

De Fruyt • De Clercq 
normal personality development and independent from overall mean-level declines over time, the results also indicated significant differential continuity, with high-scoring individuals remaining the most vulnerable over time as reflected in their enduring high scores across assessment points (Crawford et al. 2005).

These prospective findings on PD symptoms (as operationalized by the DSM) in younger age groups are almost exclusively described by the CIC study, making it difficult to verify whether these trends are replicable across samples. This replicability of stability and change findings, however, is a crucial issue because stability is traditionally assumed to be one of the key elements that distinguish a personality-related problem from another mental disorder (APA 2013). It is important to note that the lack of replicability results not only from a paucity of research that has focused on the longitudinal course of PD symptoms but also from differences in operationalizations of the PD construct.

From a categorical perspective, the above-mentioned findings of the CIC study suggest that there is evidence of significant instability of PD symptoms across time, but these findings may to some extent also be explained by threshold effects associated with a categorical PD operationalization or with symptomatic changes that may result in shifts toward other diagnostic categories (Krueger 2005). When described dimensionally, there is evidence that personality pathology is far less instable, a finding that can be framed in the two-component model that has been proposed by Clark (2007) and elaborated for borderline PD by Zanarini and colleagues (2005). This model identifies both stable and fluctuating symptoms within PD diagnoses and may offer an explanation for the diversity in stability findings of personality pathology across age groups. In this framework, the more stable aspects of personality pathology can be understood as temperamental symptoms that are linked to genetic and biological mechanisms, whereas the more fluctuating characteristics are embedded within learning and developmental processes (Skodol et al. 2005). These temperamental symptoms can be hypothesized to have a trait-like character and may therefore be described within a dimension-oriented framework from childhood onward.

Studies of adults have indicated that the use of a dimensional approach for examining the longitudinal behavior of personality pathology generally results in findings of a higher stability of personality pathology symptoms over time. However, almost no studies exist on the meanlevel behavior of personality pathology traits in younger age groups. De Clercq et al. (2009) have demonstrated in a prospective study that the two-year course of age-specific maladaptive traits is characterized by a similar maturation principle as in adulthood, showing small but significant declines of personality pathology over time and thus indicating a gradual movement toward greater personality maturity. From an individual perspective, the results showed that children with highscoring profiles of personality pathology appeared to be at higher risk of continuing this PD vulnerability over time, whereas rank-order analyses indicated a significant continuity across oneand two-year time intervals. A recent meta-analysis by Ferguson (2010) has broadened this evidence on the rank-order stability of early maladaptive traits and demonstrated that PD symptoms are moderately stable in childhood, followed by an increase in stability during early adolescence, and finally a peak in stability around the age of 30 . Various studies have similarly suggested that the rank-order stability of borderline personality disorder traits during adolescence is high and similar to the stability found in adulthood (Bornovalova et al. 2009, Lenzenweger 1999).

\section{The Developmental Principles of Equifinality and Multifinality}

Developmental pathway studies have shown that substantial variability exists in growth trajectories of childhood psychopathology across time, including aspects of both homotypic and heterotypic development that shape early maladaptation toward adult personality pathology, other mental

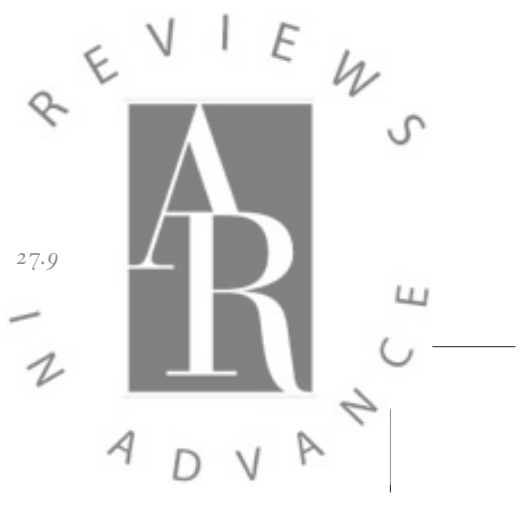


disorders, or a healthy condition. Two principles that may help frame these variabilities are equifinality and multifinality (Cicchetti \& Rogosch 1996). The concept of equifinality indicates that multiple childhood conditions may precede a single adult outcome, whereas multifinality reflects the idea that a single childhood condition may develop into diverse adult outcomes. These principles have been discussed mainly in studies that focus on phenotypic expressions of psychopathology (e.g., Broeren et al. 2013, Penney \& Moretti 2010, Rudolph et al. 2013), and they have unraveled some of the complexity of human development by empirically showing that various vulnerabilityoutcome relations throughout development can be understood as manifestations of the same principles. Although this evidence has created a more systematic descriptive framework for understanding the wealth of findings on developmental psychopathology, it remains a dense task to theoretically define how personality develops owing to the interactive contributions of various environmental aspects as well as the biological influences on our individual differences system.

\section{The (Neuro)Biological and Genetic Underpinnings of Personality Disorders}

Recent technological developments in the area of genetics and neurobiology have created the opportunity to advance research on PD antecedents at the biological level. Although the belief in the biological basis of personality can be traced back to the ancient Greeks, only recently has science been able to empirically examine how genes and biological systems, including brain function and the role of neurotransmitters, account for phenotypic behavior from childhood onward. A recent and comprehensive overview on this biological basis (Rettew 2013) made four important notes regarding the interpretation of the biological roots of personality.

First, although different areas of the human brain are connected to particular functions, the manifestation of traits (and related to this, trait pathology) involves the networking of multiple regions; in other words, there is no one-to-one relationship between a specific brain region and a certain trait. An area of particular interest with regard to personality symptoms is the amygdala, which is responsible for emotion regulation. The amygdala has been consistently hypothesized to be related to the trait negative emotionality (Canli 2008), one of the key trait components across various personality disorders. It is important to understand, however, that studying the functional connectivity of the amygdala with other brain regions, such as the anterior cingulate cortex, provides a more realistic perspective on how emotion dysregulation problems are reflected at the biological level (Rettew 2013). This has been recently illustrated by Ormel and colleagues (2013), who showed that elevated scores on neuroticism are characterized at the biological level by weaker connectivity between the left amygdala and the anterior cingulate cortex.

Second, reducing the etiology of psychiatric disorders such as PDs to an imbalance in neurotransmitters or hormones (Rettew 2013) harms the complex reality. However, a number of neurotransmitters have been specifically identified as etiological factors involved in the development of PDs, including dopamine, serotonin, and noradrenaline. Although the biopsychological models that associate these neurotransmitters with personality have a strong heuristic value (Paris 2005), much more research is required to explore their specific role as well as their connection with the genes that encode for the neurotransmitters and their functioning.

Third, many biological determinants of temperament or personality have been proposed previously as important etiological factors of psychiatric disorders, potentially suggesting that the interconnection between normal and abnormal personality development is also significant at a neurobiological or genetic level. For example, from a continuum perspective on the trait-disorder relationship it has been demonstrated that the genetic influence of the temperamental trait that represents the conscientiousness domain is the same as the genetic liability to develop ADHD (Goldsmith et al. 2004). As reviewed in Rettew (2013), similar common genetic or biological

De Fruyt • De Clercq 
underpinnings for traits and specific disorders have been found in adult twin studies, suggesting that the etiological roots of traits and disorders have a commonality that is reflected at the most essential level of human nature.

Finally, genetic and environmental components that contribute to the expression of traits are not distinct but rather are highly interconnected, as mirrored in gene-environment correlations (McGowan et al. 2009) and gene-environment interactions (Belsky \& Pluess 2009, Dick 2011, Ellis et al. 2011, Rutter 2012, Wilkinson et al. 2013). In this respect, a common misperception exists that genes and environment have only an independent impact on personality development; in contrast, there are multiple paths through which they appear to influence traits and disorders. When focusing on the etiology of PDs, it is important to consider these interactive and correlational mechanisms between environment and genes or neurobiological substrates as well as the direct effect of environment on genes or brain function that are related to traits. Such research has been termed "epigenetics" and was recently used to examine environmental effects on gene expression involved in the development of stress regulation, one of the key areas related to several PDs. The interrelatedness of biologically based traits with environmental aspects should also be broadened to include the concept that the expression or manifestation of traits can be triggered by certain environmental aspects, as outlined in trait activation theory.

\section{Trait Activation Theory}

Children's and adolescents' characteristic ways of thinking, feeling, and behaving do not deploy in a vacuum and need to be considered in their interpersonal and broader situational context. These contextual factors have been mainly ignored in trait psychology, although recently a growing research field has examined reciprocal influences between characteristic manifestations, their underlying traits, and situational factors. Although personality traits have shown strong genetic underpinnings, situational influences cannot be excluded. Apart from situational main effects, such influences may be important for at least three different reasons.

First, given their genetic make-up, individuals may seek out environments that are compatible with their traits; in this case, the situation contributes to personality stability. For example, a sensation-seeking, irritable, and rule-breaking youngster may be attracted by street gangs and may cultivate externalizing and other forms of deviant behavior in an attempt to gain control of a city neighborhood. Second, contexts may positively or negatively reinforce children's and adolescents' behavior patterns, and the study of such contingencies may lead to a better understanding of an individual's development and current (problematic) functioning. For example, an intellectually gifted adolescent scoring low on achievement motivation may exhibit a downward career track in secondary school and may end up in even less-challenging learning environments, further affecting his intellectual development. Third, contexts may trigger certain behavior that was dormant in the child's or adolescent's personality, and (mal)adaptive behaviors may pop up under specific conditions of stress, strain, or fatigue. These three examples illustrate that we need a developmental model that captures complex trait-situation relationships from childhood onward.

In an effort to understand job performance, industrial and organizational psychologists Robert Tett and Dawn Burnett (2003) introduced a personality trait-based interactionist model that can be easily adapted to advance our knowledge of developing personality pathology in childhood and adolescence. From the perspective of emerging personality pathology, this model has three core assumptions.

First, traits and environmental factors may have main effects on characteristic manifestations (behaviors, feelings, and cognitions). Second, these manifestations may be appraised as either adaptive or maladaptive, depending upon the child's or adolescent's developmental stage.

www.annualreviews.org • Childhood Antecedents of Personality Disorder

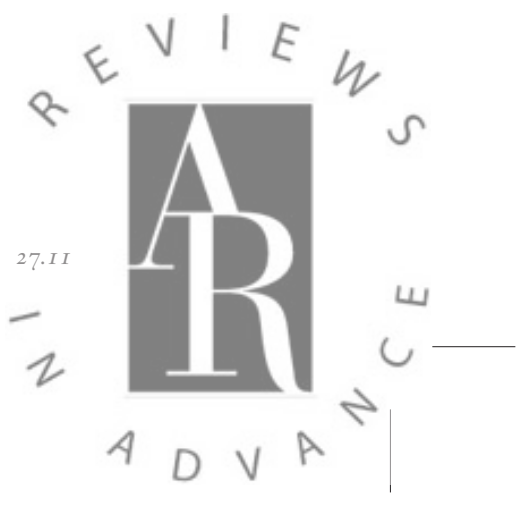




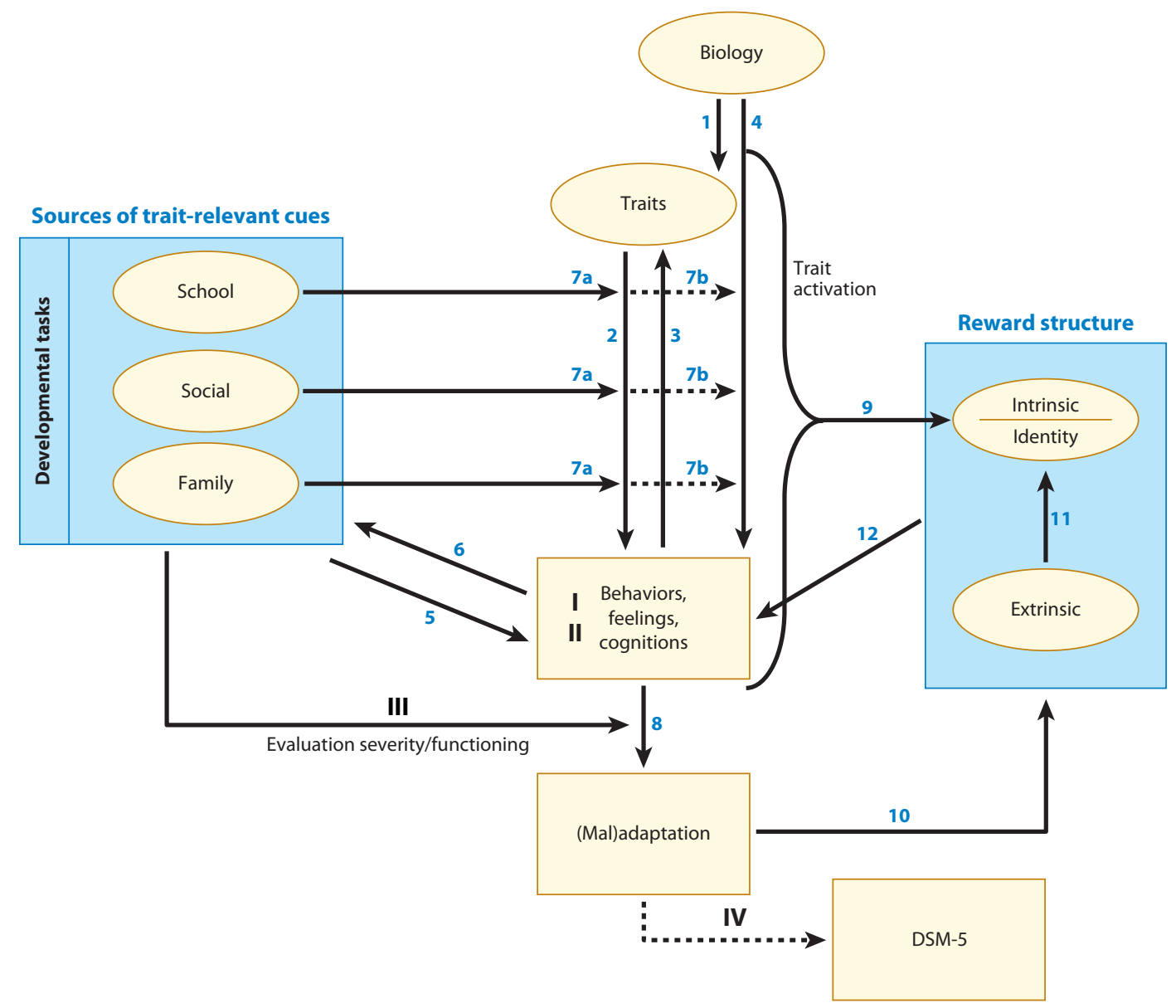

Figure 1

Integrative model of personality pathology precipitants. Note: Arabic numerals indicate paths in the model; Roman numerals refer to steps in the assessment process. Abbreviation: DSM-5, Diagnostic and Statistical Manual of Mental Disorders, fifth edition.

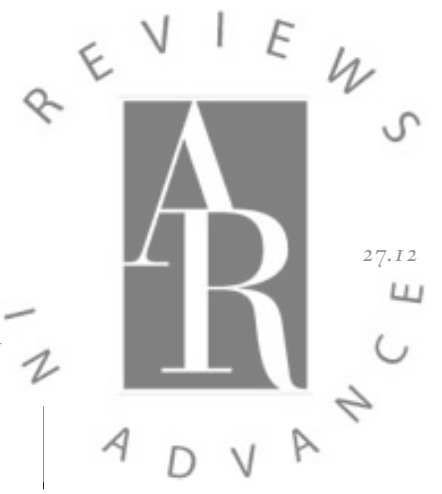

Characteristic manifestations must be evaluated as (in)appropriate or (mal)adaptive, taking into account the developmental tasks that are defined in three areas: functioning at home (family), functioning among peers (social/interpersonal), and functioning at school. Third, factors in the environment may trigger or activate latent personality tendencies that are expressed in particular behavior, feelings, and cognitions and may hence function as moderators of the basic tendencies-characteristic manifestations relationship. The amended and extended model of Tett \& Burnett (2003, p. 503, fig. 1) is described in Figure 1. Its constituting elements and paths are further described referring to numeric indices and are graphically represented by full lines in Figure 1. Deviations from Tett and Burnett's model to make it appropriate to the study of emerging personality pathology are explicitly mentioned.

Traits have a strong genetic origin, and their biological underpinnings have been the focus of intense research (Path 1 in Figure 1). They represent latent dispositions, also entitled basic tendencies in the five-factor theory (McCrae \& Costa 1996), that cannot be directly assessed but that have to be inferred from characteristic behaviors, feelings, and cognitions that are manifestations

De Fruyt • De Clercq 
of these underlying traits. Path 2 forms the core of this trait-based analysis of emerging personality pathology and shows that basic tendencies have main effects on characteristic manifestations, i.e., the behavior, feelings, and cognitions that children/adolescents exhibit at a particular moment. According to this path, basic tendencies mediate the child's biological structure and his/her behavioral, emotional, and cognitive characteristic manifestations. We also added a reciprocal path (Path 3) to indicate that enduring changes in characteristic manifestations are indicative of personality change, as well as a direct path from the genetic and biological basis to characteristic manifestations (Path 4), because not all biological influences are mediated by traits.

Path 5 refers to main effects from the environment on the characteristic manifestations in children and adolescents. The key environmental components identified in Tett and Burnett's original model are replaced by developmentally appropriate contexts including family (e.g., relationships with parents and siblings; parental behavior), the social/interpersonal environment (relationships with peers and friends), and the school setting. The developmental life tasks that are specified for youths are closely intertwined with functioning in each of these environmental arenas. For example, family-related factors such as depression or a borderline diagnosis of the mother may have a direct impact on the child's characteristic manifestations via the family climate ${ }^{2}$ (Herr et al. 2008). Likewise, attitudes, habits, and role expectations within a child's peer group may influence the child's behavior (Dishion \& Tipsord 2011), and the school setting may impact the child's well-being (Konu et al. 2002). This relationship is further bidirectional, as the child's characteristic behaviors, feelings, and cognitions may also directly influence the environment (Path 6). For example, children exhibiting externalizing behavior challenge their environment in terms of rearing and manageability skills (Burke et al. 2008).

Beyond these main effects, environmental factors may further act as activators of basic tendencies that lead to specific manifestations of behavior, feelings, and cognitions (Paths $7 a$ ). These three contexts hence act as moderators of the trait-characteristic manifestation path, triggering, for example, specific trait vulnerabilities or interacting with certain trait expressions and thus molding the way specific behavioral patterns, feelings, and cognitions are phenotypically expressed. Van Leeuwen et al. (2004b), for example, demonstrated that parental behavior moderated the relationship between a child's personality and the level of problem behavior, suggesting that disagreeable children are especially at risk to develop problem behavior when parents act in a negative controlling way. Laceulle et al. (2012) showed that stressful events moderated normative personality development in adolescence. The same contexts may also moderate Path 4, impacting direct biological influences on characteristic manifestations (Paths $7 b$ ). In a related vein, these trait-activation examples can be understood as person-environment interactions that can be framed within the differential susceptibility paradigm, indicating that individuals differ in their (neurobiological) susceptibility to their environment in regulating environmental effects on adaptation or maladaptation (Ellis et al. 2011).

Tett \& Burnett (2003) distinguish between behavior at work and job performance, the latter referring to the appraisal of the behavior in terms of desired work outcomes. This distinction also applies to the evaluation of children's characteristic manifestations, which may be interpreted as functional or dysfunctional. Behaviors, feelings, and cognitions are not necessarily adaptive or maladaptive as such, although they require an evaluation against the normative tasks and expectations that are linked to the specific developmental stage of the child. An evaluation of whether a characteristic manifestation is either adaptive or maladaptive, including an estimate of its severity, needs to be made separately (Path 8). The three specified environmental contexts further identify

${ }^{2}$ Note that there may be also a genetic path via inherited traits.

www.annualreviews.org • Childhood Antecedents of Personality Disorder

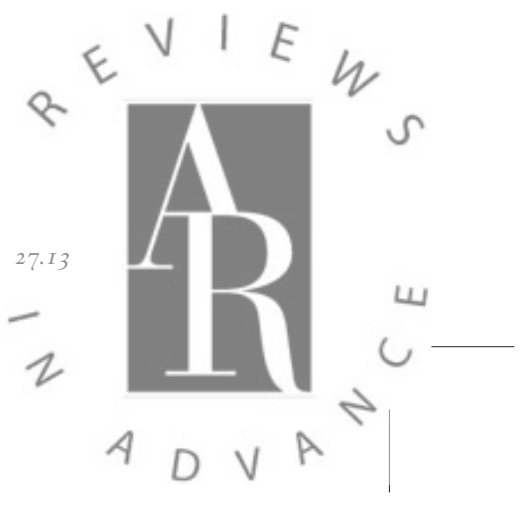


additional sources of information, i.e., parents, peers, and teachers, to provide ratings on symptom content and dysfunction severity. In order to be evaluated as maladaptive, we suggest that characteristic manifestations will need to be stable across more than six months and have a pervasive impact. This period of stability is explicitly shorter than that for the adult proposal [i.e., one year as indicated by APA (2013)] and can be advocated from the much more rapid development of children in comparison with adults.

The major path between traits and characteristic behaviors, feelings, and cognitions (path 2), incorporating potential moderating effects of the environment (Paths 7a), forms the heart of the trait-activation process. Together, these different paths form an intrinsic reward structure (Path 9) for the child/adolescent because the opportunity to give expression to one's traits, eventually moderated by environmental factors, is experienced as intrinsically rewarding, and a lack of fulfillment dissatisfies the organism (Allport 1951). These contingent associations cumulate in a characteristic set of behaviors, feelings, and thoughts contributing to the identity of the child/adolescent.

The appraisal of the characteristic behavior, feeling, and cognition patterns, based upon the functioning of the child or adolescent within the three environmental contexts, also leads to extrinsic rewards (Path 10). Such extrinsic rewards may be either positive or negative and further affect the intrinsic reward structure (Path 11). The total reward structure, including intrinsic and extrinsic elements, further affects the characteristic manifestations and eventually contributes to their continuity or change (Path 12). This integrative model can be further extended to direct paths from the environment to the reward structure in order to explicitly incorporate motivational applications, and to paths between the environment and the biological basis to account for gene-environment correlations and interactions impacting characteristic manifestations [see, e.g., work by Nederhof et al. (2010) showing that effortful control was predicted by the interaction among brain-derived neurofactor val66met, 5HT-transporter-linked polymorphic region, and childhood adverse events, or the seminal work of Caspi and colleagues (2002) demonstrating that genotypes can moderate a child's sensitivity to abuse.] In order to keep the model parsimonious and transparent, these paths are not explicitly drawn in Figure $\mathbf{1 .}$

This trait activation-based model of personality pathology accommodates all previously described etiological models to explain trait-psychopathology relationships. The vulnerability and continuity models can be described along Paths 2 and $7 a$, suggesting direct or moderated effects of traits on characteristic manifestations that are judged dysfunctional, whereas complication or scar effects are modeled via the reciprocal Path 3. Factors beyond traits, either biological or environmentally based, may further affect characteristic behaviors, feelings, and cognitions, and this expression may be colored by the presence of traits. In order to accommodate such pathoplasty effects, additional paths have to be included in Figure 1, starting from traits to Paths 4 and 5 .

\section{PROPOSAL FOR AN INTEGRATIVE PERSONALITY ASSESSMENT IN CHILD AND ADOLESCENT DIAGNOSTICS}

A major advantage of the neglect of PD precursors in official descriptive taxonomies of mental disorders is that it leaves open the road for suggestions on how to conceptualize, map, and assess developmental trajectories of emerging personality pathology. Unlike for personality pathology in adulthood, there is no established diagnostic system with a variety of academic and professional proponents and opponents. At the same time, recent discussions on the conceptualization of PDs in adulthood (Skodol 2012, Widiger et al. 2009b) and the current review and integrative scheme provide directions on how precipitant PD conditions may be conceptualized.

Given the difficulties with categorical diagnoses in adulthood and the reluctance to use stigmatizing diagnostic labels in childhood and adolescence, it is probably more appropriate to provide

De Fruyt • De Clercq 
a description of personality traits for younger age groups that may be evaluated as problematic instead of relying on PD categories. The proposed integrative model demonstrates that manifestations of (configurations of) traits are not necessarily maladaptive per se, although they may be dysfunctional under particular circumstances and/or in particular life phases.

De Fruyt and colleagues (2009b) and Wille et al. (2013) recently illustrated this point in adulthood, showing that increased scores on FFM PD compounds were associated with desired outcomes, suggesting that "dark traits" may also have positive outcomes. Wille et al. (2013) showed concurrently, but also across a 15 -year time span, that individuals with increased scores on the FFM borderline, schizotypal, and avoidant PD compounds had less favorable intrinsic career outcomes, reflected in lower job and career satisfaction and higher perceived job stress, but also that those with antisocial and narcissistic tendencies obtained higher positions and greater salaries. Although these results are based upon a nonclinical group, this work illustrates that, when using a trait system, impairment cannot be assumed automatically but rather needs to be considered specifically and dynamically. The label "dysfunction" instead of "disorder" probably better captures this necessity.

Finally, an assessment model proposed for the description of personality pathology precipitants in childhood and adolescence needs to be congruent with its adult counterpart so both approaches can be easily aligned into an integrative assessment model for personality pathology across the life span. Rather than focusing on a risk assessment for specific PDs as listed in section II of DSM-5 (APA 2013), we advocate an assessment in terms of a description of a set of broad personality traits, complemented with an assessment of (dys)function or severity. This proposal is further in line with alternative calls to assess PDs in adulthood (Widiger \& Mullins-Sweatt 2009, Widiger \& Samuel 2005), which has also been suggested for ICD-11 (Tyrer 2012, 2013) and is included in section III of DSM-5 (APA 2013, pp. 761-781) to be the subject of further research and evaluation.

\section{Trait Assessment}

In the run-up toward DSM-5, Widiger et al. (2009b) proposed a dimensional model that uses general and maladaptive trait measures to describe personality pathology in adulthood. The first step in this proposed assessment cycle involves a description on a comprehensive general trait measure followed by an evaluation of meaningful deviations on one or more of the main personality dimensions. Consistent with the continuity/spectrum hypothesis, deviations can be either meaningfully beyond or above the mean. This first assessment phase has to identify those individuals with extreme scores on general traits who require additional evaluation using measures that are specifically designed to tap into more maladaptive personality descriptive content, such as the DAPP-BQ (Livesley 1990) or the SNAP (Clark 1993).

An analogous two-step assessment for younger age groups can be proposed using the NEOPI-3 (De Fruyt et al. 2009a, McCrae et al. 2005), which has been shown to be applicable in adolescence, or the HiPIC (Mervielde et al. 2009) or ICID (Halverson et al. 2003) as broad general trait inventories for children. These can be supplemented in a second step by trait measures that better differentiate in terms of potential maladaptive descriptive content, such as the DAPP-BQAdolescent Form (Tromp \& Koot 2008), an adolescent version of the Schedule for Nonadaptive and Adaptive Personality for Youth (SNAP-Y; Linde et al. 2013), or the DIPSI (De Clercq et al. 2006), which was specifically designed for children.

DSM-5 (APA 2013) has imported the DSM-IV-TR (APA 2000) PDs and their diagnostic criteria, although it also included a trait model referred to in section III that requires further evaluation and research. One operationalization of this model, the Personality Inventory for DSM-5 (PID-5; Krueger et al. 2012), represents a higher-order structure of five major dimensions labeled as negative affectivity, detachment, antagonism, disinhibition, and psychoticism, with a set

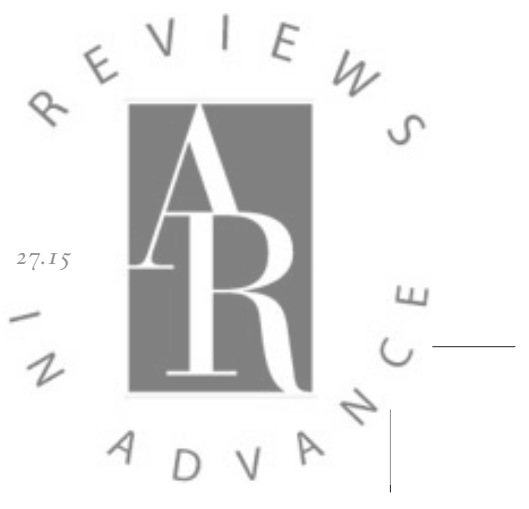


of 25 lower-order traits provisionally mapped onto this five-factor structure. De Clercq and colleagues (2014b) recently examined whether this DSM-5 trait system is also useful in preadulthood, and they administered the PID-5 to adolescents. The results showed that the scales had generally acceptable-to-good internal consistencies but that the higher-order structure differed slightly from the adult structure, perhaps due to developmental issues.

Finally, an extreme score on a general trait or even on a trait tapping into more maladaptive content is not pathological or dysfunctional in itself, so in line with the integrative model advocated previously, judgments on severity need to be made separately from the description of characteristic manifestations in step 3. Ultimately, this distinction is more conceptual than operational because both overlap to some extent (Bastiaansen et al. 2014). From an assessment point of view, however, we suggest including a separate evaluation of "dysfunction" in step 3 given that such appraisal includes a contextualized evaluation of the child's or adolescent's behavior, taking into account his/her interpersonal network and current life tasks.

\section{Categorical Recapitulation}

This primary three-step trait-based process can be supplemented with a fourth step to produce a translation of trait scores into a DSM-5 categorical diagnosis. Such an additional step involves the grouping of traits into meaningful clusters of traits relying on cut-off scores. Different options are available to use such a trait-based system for the diagnosis of PDs, and within DSM-5 (APA 2013) two possible avenues have been suggested. A first option is to identify heightened scores on a set of traits that are considered prototypical for six specific PDs, namely the schizotypal, antisocial, borderline, narcissistic, dependent, and obsessive-compulsive PDs. The second route is a PD trait-specified diagnosis, with elevated scores demonstrated on one or more of these higherorder personality dimensions, or specific facets within these domains, considering all higherorder dimensions. In both options, before a PD can be diagnosed, elevations on traits should be accompanied by moderate-to-extreme impairment in personality functioning manifested in two or more of four areas, including identity, self-direction, empathy, and intimacy (APA 2013, p. 762). De Clercq et al. (2014a) recently examined the validity of the trait configuration suggested for the borderline PD prototype (APA 2013, pp. 766-767) in adolescence, providing first evidence for its validity. Much work remains to be done, however, to improve and validate such trait groupings for adults (Samuel et al. 2013) and to determine whether these can be extended to youths.

\section{Paradigm Shift}

This four-step assessment process using trait dimensions can be easily projected onto the integrative trait-activation scheme, with step 1 (broad screening at the FFM level; indexed by Roman numeral I in Figure 1) of this procedure positioned conceptually at the basic tendency/trait level, although operationally to be inferred from overt behavior, feelings, and cognitions because traits are latent dispositions that cannot be observed directly. Step 2 (indexed by II), involving a more fine-grained description using trait measures representing potentially more maladaptive trait variance (such as DIPSI, PID-5, SNAP-Y, DAPP-BQ-A), is also positioned the characteristic manifestation level although it falls conceptually and empirically under the umbrella of the FFM (De Fruyt et al. 2013, Gore \& Widiger 2013). The assessment of dysfunction and severity (step 3, indexed by III) is captured by the arrow pointing from the environmental sources of traitrelevant cues onto Path 8 , resulting in a dysfunction and severity rating, eventually split up per area (family, social, or school). Finally, if clinicians wish to obtain a categorical DSM-5 diagnosis in those instances that meet all specified criteria, then traits can eventually be regrouped into PD prototypes (step 4, indexed by IV).

De Fruyt • De Clercq 
It should be clear, however, that we basically advocate a description of children and adolescents in terms of a broad set of traits (steps 1 to 3 ) rather than arguing to systematically consider the adoption of step 4. This paradigm shift in personality and personality pathology assessment in youths is crucial for four reasons. First, it avoids labeling young people with stigmatizing diagnoses of difficult-to-treat and severely impairing disorders whose conceptual status has been heavily discussed in past years (Widiger \& Clark 2000).

Second, this paradigm transference may also help to decrease the number of other childhood diagnoses that are so far not considered as PDs but show a clear association with personality traits (e.g., ADHD), avoiding diagnostic inflation or epidemics of psychiatric fads (Frances \& Widiger 2012). For example, the ADHD category has different subtypes (Frick \& Nigg 2012), and some children who are diagnosed with ADHD may simply demonstrate behavior that is indicative of a more elevated standing on general trait measures.

Third, the expression of personality (in development) does not appear in a vacuum and hence is not context free. The implication is that assessment will also need to consider the environment in which the child/adolescent is growing up and that may serve as a trigger and/or reinforcer of certain personality manifestations. The previously described integrative scheme for emerging personality difficulties creates the opportunity to model and study such developmental trajectories.

Finally, this shift toward trait descriptions rather than categorical PD diagnoses also opens possibilities for focusing on strengths instead of describing a child only in terms of vulnerabilities or deficiencies.

\section{CHALLENGES AND OPPORTUNITIES FOR THE DOMAIN OF PERSONALITY PATHOLOGY PRECIPITANTS}

The current review closes with a number of suggestions for future research lines that may advance this promising field.

\section{Revisiting the Artificial Distinction Between Temperament and Personality}

Early observable differences among toddlers and young children have been traditionally denoted as differences in temperament in the developmental psychology literature, with various models that differ in terms of the number and nature of the dimensions that are proposed. The absence of a consensus among temperament researchers on the basic dimensions of temperament prevented for years an in-depth study of the associations between temperament measures and psychopathology.

Inspired by the consensus and especially the scientific progress that the FFM brought to the personality field, the International Consortium for the Study of the Developmental Antecedents of the Five-Factor Model (Kohnstamm et al. 1998) used a classification framework to structure parental free descriptions of children's personality, consisting of the FFM complemented with categories referring to temperament constructs such as rhythmicity and independence. When the content enclosed in this lexical classification framework was represented, it became clear that it was not tenable at an operational level to distinguish between a so-called temperament and a personality item. Moreover, a growing literature indicated that FFM traits were also observable in younger age groups (Digman 1963, Mervielde et al. 1995), showed a certain stability across time (De Fruyt et al. 2006), and were strongly biologically driven. These results led Caspi et al. (2005) to the conclusion that temperament and personality traits are more alike than different and that the two terms could be used interchangeably.

These claims were supported by a classification analysis by Mervielde \& Asendorpf (2000) accommodating the temperament models of Thomas \& Chess (1977), Buss \& Plomin (1975),

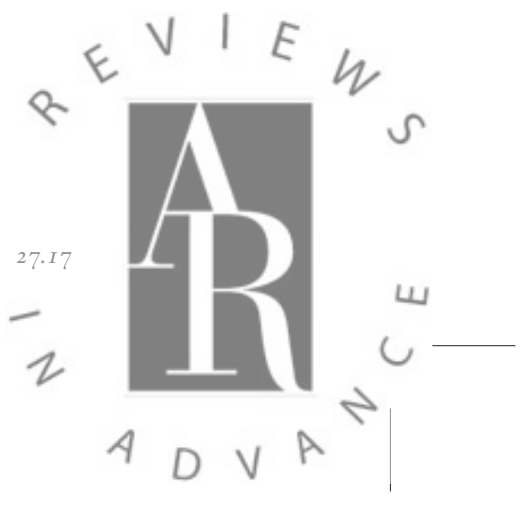


Rothbart \& Derryberry (1981), and Goldsmith \& Campos (1982) in the FFM structure. The FFM scheme showed that neither agreeableness nor openness/intellect was well captured by temperament constructs, despite the fact that agreeableness is a prominent trait in the childhood/adolescent personality literature (Graziano \& Eisenberg 1997) and is important in understanding different forms of externalizing behavior from childhood to adulthood (Decuyper et al. 2009; Van Leeuwen et al. 2004a,b).

Support for this conceptual analysis was provided by De Pauw et al.'s (2009) empirical examination of the overlap between the dimensions of the HiPIC (Mervielde et al. 2009) and three different temperament models. Although this research suggests that temperament measures include specific variance to understand psychopathology beyond the FFM, this research is constrained to one personality inventory (i.e., the HiPIC) that represents the active personality-descriptive vocabulary of parents. The lexical approach, although important, is only one way to define the domain of personality differences, and its limitations have been recently demonstrated in the discussion on the validity of the HEXACO personality inventory model. A reanalysis of these data (Ashton et al. 2004) demonstrated that even lexical researchers had difficulty identifying a neuroticism/emotional stability factor (De Raad et al. 2010), a key dimension of personality that is represented in most personality theories.

Taken together, it is clear that the distinction between temperament and personality reflects semantics more than substance, so it is probably time to merge these two fields. As it stands now, the FFM seems to be the model par excellence to adopt in our integrative developmental scheme of emerging personality pathology.

\section{Expanding and Psychometrically Redesigning Current Childhood/Adolescent Trait Measures}

The currently available measures to assess more maladaptive personality traits in childhood/ adolescence are certainly not optimal from either a taxonomic or a psychometric point of view, particularly when they need to be applied in the previously described assessment process. First, personality pathology inventories that were developed for adults and adapted for use in adolescence, such as the DAPP-BQ-A (Tromp \& Koot 2008) or the SNAP-Y (Linde et al. 2013), provide no guarantees that they adequately represent those maladaptive traits necessary to sufficiently tap all early signs of personality pathology observable in children or adolescents, taking into account the concepts of equi- and multifinality. Given their top-down application to young age groups, one cannot exclude that trait constructs have to be assessed differently or that some traits are simply missing. In addition, the DIPSI (De Clercq et al. 2006) did not have a separate factor and facets tapping into the oddity domain (Chmielewski \& Watson 2008) in its initial form. At the time of the construction of the item pool, the authors decided not to write maladaptive variants of the items enclosed in the intellect, creativity, and fantasy facets of the HiPIC imagination factor. Today, however, a module covering the oddity domain in childhood and adolescence has been developed (Verbeke \& De Clercq 2014) and includes trait facets such as oversensitivity to feelings (four items), extreme fantasy (five items), daydreaming (seven items), and odd thoughts and behavior (six items).

Whereas these drawbacks are mainly taxonomic, the second concern is more psychometric because almost all of these instruments are mainly constructed using traditional psychometric methods focusing on unidimensionality and internal consistency. Given the central importance of adequately positioning an individual on different trait dimensions, more advanced data analytic techniques are required in order to select those items that systematically cover the full range of a trait dimension, including enough items that differentiate at the low and the high ends of

De Fruyt • De Clercq 
the respective dimensions. Promising exemplary research on how such objectives can be met for assessing personality pathology in adults was conducted by Simms and colleagues (2011) in the Computerized Adaptive Assessment of Personality Disorder project and by Stepp et al. (2012c), who integrated normal and maladaptive trait measures. Although we see much benefit in such integrated assessment approaches in cases with strong indications of personality pathology, we still advance a distinction in the two-step process between general and more maladaptive traits for broader screening purposes because a general trait inventory is broadly applicable and can screen for extreme scorers on trait dimensions using neutral and nonoffensive language/item content. Only individuals scoring beyond a certain threshold on general traits can be assessed more specifically, resulting in a considerably smaller number of children/adolescents who require more clinically oriented assessment, either via interview or supplementary questionnaire.

\section{Integrating Person-Centered Approaches}

Most of the research reviewed in this article is variable oriented, i.e., the structure of traits is studied across individuals. An alternative approach is a person-centered analysis, which examines the grouping of traits within individuals. In these analyses, one explores groups of individuals with similar trait patterns. The field of personality psychology has a longstanding tradition of person-centered work, resulting in three to four replicable types that have been derived from ratings on general trait measures in both childhood and adulthood (Asendorpf \& van Aken 1999). These prototypes have been labeled as resilient, overcontrolled, and undercontrolled. The resilient type represents individuals with desirable FFM trait positions, i.e., low on neuroticism and with moderate-to-high scores on the other FFM domains, whereas the overcontrolled type groups people who are more introverted and neurotic. The undercontrolled cluster includes people with, on average, low scores on agreeableness and, to a lesser extent, conscientiousness. Each of the three trait types is uniquely related to adaptation or dysfunction over time, with systematically higher risks for the over- and undercontrolled types to develop psychopathology (Van Leeuwen et al. 2004a). Overall, these person-centered studies learned that it is useful to look at configurations of traits that naturally occur in the population.

Such person-centered approaches have also been applied to maladaptive trait models in adulthood (Eaton et al. 2011), with a wide range of resulting cluster or latent class patterns that seemed at first difficult to link with existing PD symptom categories. Rather than calling for a moratorium on person-centered research, we encourage additional work taking into account the following recommendations. First, the strong data-driven nature of the analyses that are used to derive types reduces the importance of replicability of person types across samples. In addition, the significance of prototypes should not be evaluated against diagnostic categories such as the categorical DSM-5 PDs, which are themselves contested. More important is that prototypes are clinically meaningful and above all demonstrate predictive validity in terms of treatment indication and prognosis. Third, an often recurring problem is that some of the resulting latent classes reflect a similar trait configuration, though with varying intensity of the trait levels (see, e.g., De Clercq et al. 2012), like salsas that range from mildly spicy to medium and hot. ${ }^{3}$ Such results suggest that there is a common factor, probably reflecting symptom severity, that obscures a more differentiated pattern popping up at the style level. In sum, we think that person-centered analyses should receive more attention from a clinical point of view because they examine the interplay between traits at the

${ }^{3}$ We thank Dr. Robert Althoff for suggesting this analogy.

www.annualreviews.org • Childhood Antecedents of Personality Disorder

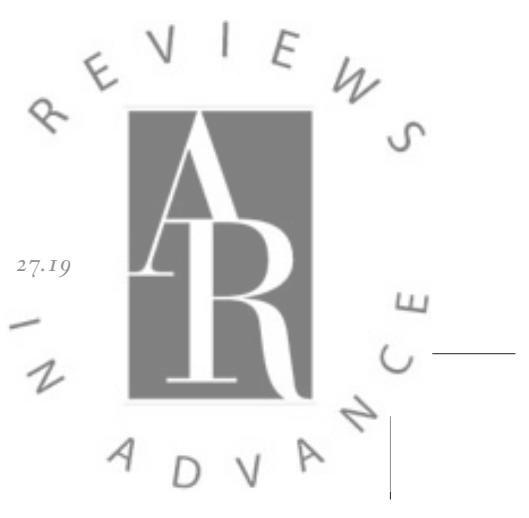


individual level, much as a clinician examines a child from a holistic point of view (De Clercq et al. 2012).

\section{Focusing on Early Intervention}

Given that personality stability increases with age (Caspi et al. 2005), it is reasonable to suggest that characteristic manifestations of personality are more malleable in childhood and adolescence. Relatedly, therapeutic efforts may have the largest effects during these early life stages. The domain of interventions targeted at developing personality difficulties, however, is one of the most understudied for reasons that can be understood from the issues raised above. At this point, the introduction of the integrative model that has been outlined may help to identify objectives for intervention during the developmental process of personality pathology. First, interventions can be directed at environmental aspects that may directly impact characteristic manifestations (Path 6), such as a parenting supportive program in families with mothers who are diagnosed with borderline personality disorder. Such programs stimulate positive parental skills, including warmth, nurturance, and responsiveness, and have been systematically related to more positive childhood outcomes (Stepp et al. 2012b). Schaeffer \& Borduin (2005) have demonstrated that multisystemic therapy in violent juvenile offenders resulted in long-term reduced criminal activity. A second type of intervention may be directed at the moderation (Paths $7 a$ ) of sources of trait-relevant cues and of the effect between traits and characteristic manifestations. For example, an intervention may be targeted at identifying and coping with stressful triggers at school so that children with a highly neurotic disposition have a reduced risk of developing overanxious behavior in contexts where they have to perform. From a similar interactional perspective, Stoltz et al. (2013) further showed that conscientiousness moderated the short-term effects of a school-based intervention for preventing externalizing behavior, whereas extraversion moderated both short-term and long-term effects. Although this intervention was primarily targeted at the level of the school, these results suggest that personality descriptions of the target group may help to identify prognostic information.

A third potential therapeutic objective is to intervene at the level of the reward structure and to focus, for instance, on desired positive/negative extrinsic rewards that contribute to a child's expression of his/her personality traits. Finally, interventions can be centered on the environment itself and can focus on the selection of environments that create a better fit with the child's personality. This goodness-of-fit may in turn lead to an evaluation of the child's characteristic manifestations as less maladaptive. From a strictly medical model, interventions can also be directed at the path that goes from biology toward characteristic manifestations, suggesting that psychopharmaca may reduce the impact of disturbed neurotransmitter systems on specific behavior or feelings, for instance. Reliable studies on the effect of psychopharmacological interventions in PDs are still scarce, however. Much more research is needed in this regard before a specific medical intervention policy for younger age groups can be considered.

Finally, moving from intervention to prevention, maladaptive trait trajectories may also be influenced by interventions that focus on general population samples. Raine and colleagues (2003), for instance, have convincingly shown that a nutritional, educational, and physical exercise enrichment program in a general population sample of young children was associated with lower scores on schizotypal traits and antisocial behavior.

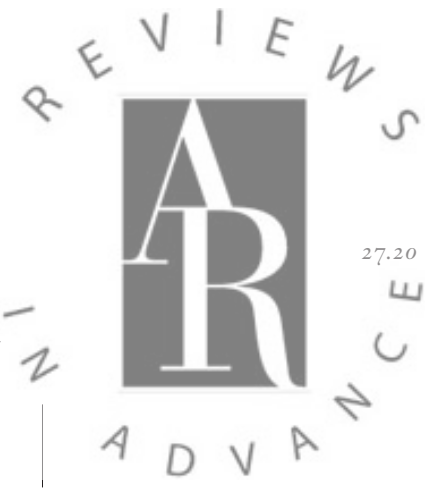

\section{CONCLUSIONS}

The diagnosis of PD in young individuals is an extremely delicate issue because for years an academic and clinical culture has associated this label with unchangeability. The revolutionary shift

De Fruyt • De Clercq 
away from PD as a rather stigmatizing diagnosis and toward its description in terms of underlying dimensional trait components not only has made personality difficulties in general more workable psychiatric conditions but has also gradually created a more progressive perspective on the developmental processes that precede the adult manifestations of personality pathology. However, the number of players in this field is small, possibly because the main resources of research funding continue to focus on the adult psychiatric field of personality pathology, where an established framework has been structured to study disturbances in personality. This lack of a conceptual framework for understanding personality problems in younger age groups may be an additional reason why many personality researchers have been reluctant to focus their studies on PD precipitants. The present review aims to advance this field and proposes an integrative model of personality pathology development in childhood or adolescence that incorporates various mechanisms of personality development that have been proven empirically valid and relevant. We hope that an increasing number of clinicians will be inspired to recognize personality difficulties in younger age groups as essential constructs of interest after taking under consideration (a) the growing evidence of the predictive validity of early personality problems for a variety of psychosocial outcomes, $(b)$ the biological origins of personality difficulties, along with their connection with general traits and the similarity of their longitudinal behavior in comparison with that defined for adults, and (c) the efficacy of early intervention programs.

\section{SUMMARY POINTS}

1. The study of antecedents of personality disorder in childhood and adolescence is an established research field.

2. Personality differences and emerging personality difficulties in childhood and adolescence are preferably examined and described along the dimensions of the five-factor model to avoid categorical personality disorder diagnoses or descriptions on an amalgam of temperament constructs.

3. A three- to four-step assessment process of personality pathology precipitants is proposed.

4. An integrative model of personality pathology precipitants for childhood and adolescence is available now; it accommodates different etiological models of trait-psychopathology relationships, identifies major environmental influences, and pinpoints targets of early intervention.

\section{FUTURE ISSUES}

1. Longitudinal research starting in childhood is needed in which developmental trajectories are mapped using comprehensive general and maladaptive trait measures, including a detailed assessment of environmental factors.

2. Studies on the effects of early intervention programs should be a priority.

\section{DISCLOSURE STATEMENT}

Filip De Fruyt receives royalties for the Hierarchical Personality Inventory for Children. The authors are not aware of any other affiliations, memberships, funding, or financial holdings that might be perceived as affecting the objectivity of this review.

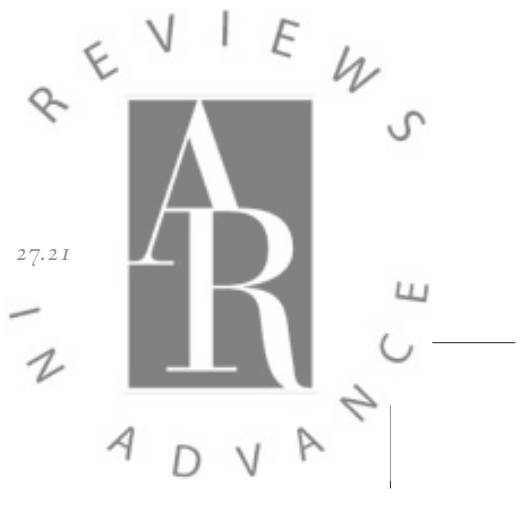


This editorial introduces a special issue compiling a set of challenging papers

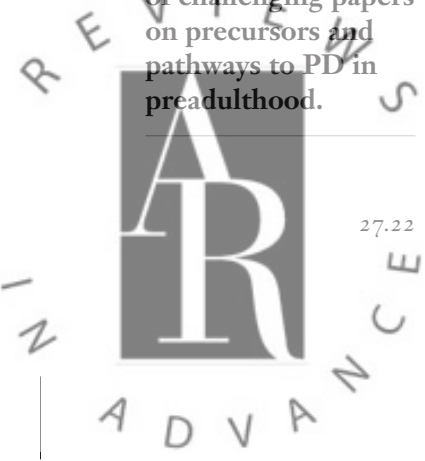

\section{LITERATURE CITED}

Achenbach TM. 1991. Manual for the Child Behavior Checklist/4-18 and 1991 Profile. Burlington: Univ. Vt. Dep. Psychiatry

Aelterman N, Decuyper M, De Fruyt F. 2010. Understanding obsessive-compulsive personality disorder in adolescence: a dimensional personality perspective. 7. Psychopathol. Behav. Assess. 32(4):467-78

Allport GW. 1951. Personality - A Psychological Interpretation. London: Constable

Am. Psychiatr. Assoc. (APA). 1980. Diagnostic and Statistical Manual of Mental Disorders. Washington, DC: Am. Psychiatr. Publ. 3rd ed.

Am. Psychiatr. Assoc. (APA). 1987. Diagnostic and Statistical Manual of Mental Disorders. Washington, DC: Am. Psychiatr. Publ. 3rd ed., rev.

Am. Psychiatr. Assoc. (APA). 1994. Diagnostic and Statistical Manual of Mental Disorders. Washington, DC: Am. Psychiatr. Publ. 4th ed.

Am. Psychiatr. Assoc. (APA). 2000. Diagnostic and Statistical Manual of Mental Disorders. Washington, DC: Am. Psychiatr. Publ. 4th ed., text rev.

Am. Psychiatr. Assoc. (APA). 2013. Diagnostic and Statistical Manual of Mental Disorders. Arlington, VA: Am. Psychiatr. Publ. 5th ed.

Asendorpf JB, van Aken MAG. 1999. Resilient, overcontrolled, and undercontrolled personality prototypes in childhood: Replicability, predictive power, and the trait-type issue. F. Personal. Soc. Psychol. 77(4):815-32

Ashton MC, Lee K, Perugini M, Szarota P, de Vries RE, et al. 2004. A six-factor structure of personalitydescriptive adjectives: Solutions from psycholexical studies in seven languages. F. Personal. Soc. Psychol. 86(2):356-66

Bastiaansen L, De Fruyt F, Rossi G, Schotte C, Hofmans J. 2014. Personality disorder dysfunction versus traits: structural and conceptual issues. Personal. Disord. Theory Res. Treat. In press

Belsky J, Pluess M. 2009. Beyond diathesis stress: differential susceptibility to environmental influences. Psychol. Bull. 135(6):885-908

Block J, Block JH. 1980. The California Child Q-Set. Palo Alto, CA: Consult. Psychol. Press

Bornovalova MA, Hicks BM, Iacono WG, McGue M. 2009. Stability, change, and heritability of borderline personality disorder traits from adolescence to adulthood: a longitudinal twin study. Dev. Psychopathol. $21: 1335-53$

Broeren S, Muris P, Diamantopoulou S, Baker JR. 2013. The course of childhood anxiety symptoms: developmental trajectories and child-related factors in normal children. F. Abnorm. Child Psychol. 41:8195

Burke JD, Pardini DA, Loeber R. 2008. Reciprocal relationships between parenting behavior and disruptive psychopathology from childhood through adolescence. F. Abnorm. Child Psychol. 36:679-92

Buss AH, Plomin R. 1975. A Temperament Theory of Personality Development. New York: Wiley

Canli T. 2008. Toward a neurogenetic theory of neuroticism. In Molecular and Biophysical Mechanisms of Arousal, Alertness, and Attention, ed. DW Pfaff, BL Kieffer, 1129:153-74. Malden, MA: Wiley-Blackwell

Caspi A, McClay J, Moffitt TE, Mill J, Martin J, et al. 2002. Role of genotype in the cycle of violence in maltreated children. Science 297:851-54

Caspi A, Roberts BW, Shiner RL. 2005. Personality development: stability and change. Annu. Rev. Psychol. 56:453-84

Chanen AM, Kaess M. 2012. Developmental pathways to borderline personality disorder. Curr. Psychiatry Rep. 14(1):45-53

Chmielewski M, Watson D. 2008. The heterogeneous structure of schizotypal personality disorder: item-level factors of the Schizotypal Personality Questionnaire and their associations with obsessive-compulsive disorder symptoms, dissociative tendencies, and normal personality. F. Abnorm. Psychol. 117(2):36476

Cicchetti D, Crick NR. 2009. Precursors and diverse pathways to personality disorder in children and adolescents. Dev. Psychopathol. 21(3):683-85

Cicchetti D, Rogosch FA. 1996. Equifinality and multifinality in developmental psychopathology. Dev. Psychopathol. 8:597-600

De Fruyt • De Clercq 
Clark LA. 1993. Manual for the Schedule for Nonadaptive and Adaptive Personality (SNAP). Minneapolis: Univ. Minn. Press

Clark LA. 2007. Assessment and diagnosis of personality disorder: perennial issues and an emerging reconceptualization. Annu. Rev. Psychol. 58:227-57

Cohen P. 2008. Child development and personality disorder. Psychiatr. Clin. N. Am. 31(3):477-96

Cohen P, Cohen J. 1996. Life Values and Adolescent Mental Health. Mahwah, NJ: Erlbaum

Cohen P, Crawford T. 2005. Developmental issues. In Textbook of Personality Disorders, ed. JM Oldham, AE Skodol, DS Bendler, pp. 171-85. Arlington, VA: Am. Psychiatr. Publ.

Cohen P, Crawford TN, Johnson JG, Kasen S. 2005. The children in the community study of developmental course of personality disorder. F. Personal. Disord. 19(5):466-86

Costa PT, McCrae RR. 1992. Revised NEO Personality Inventory and Five-Factor Inventory Professional Manual. Odessa, FL: Psychol. Assess. Resour.

Costello AJ, Edelbrock CS, Dulcan MK, Kalas R, Klaric SH. 1984. Testing of the NIMH Diagnostic Interview Schedule for Children (DISC) in a Clinical Population: Final Rep. Cent. Epidemiol. Stud., Natl. Inst. Mental Health. Pittsburgh, PA: Univ. Pittsburgh

Crawford TN, Cohen P, Johnson JG, Kasen S, First MB, et al. 2005. Self-reported personality disorder in the children in the community sample: convergent and prospective validity in late adolescence and adulthood. 7. Personal. Disord. 19(1):30-52

Deal JE, Halverson CF, Martin RP, Victor J, Baker S. 2007. The inventory of children's individual differences: development and validation of a short version. 7. Personal. Assess. 89(2):162-66

De Bolle M, Beyers W, De Clercq B, De Fruyt F. 2012. General personality and psychopathology in referred and nonreferred children and adolescents: an investigation of continuity, pathoplasty, and complication models. F. Abnorm. Psychol. 121(4):958-70

De Bolle M, De Clercq B, Van Leeuwen K, Decuyper M, Rosseel Y, De Fruyt F. 2009. Personality and psychopathology in Flemish referred children: five perspectives of continuity. Child Psychiatry Hum. Dev. 40(2):269-85

De Clercq B, Aelterman N, De Pauw S, De Bolle M, Decuyper M, Tackett JL. 2010. Delineating childhood autism spectrum symptoms from a maladaptive trait perspective. F. Psychopathol. Behav. Assess. 32(4):529_ 36

De Clercq B, Decuyper M, De Caluwé E. 2014a. Developmental manifestations of borderline personality pathology from an age-specific dimensional personality disorder trait framework. In Handbook of Borderline Disorder in Children and Adolescents, ed. JL Tackett, C Sharp. New York: Springer. In press

De Clercq B, De Fruyt F. 2003. Personality disorder symptoms in adolescence: a five-factor model perspective. 7. Personal. Disord. 17(4):269-92

De Clercq B, De Fruyt F. 2012. A five-factor model framework for understanding childhood personality disorder antecedents. F. Personal. 80(6):1533-63

De Clercq B, De Fruyt F, De Bolle M, Van Hiel A, Krueger RF, Markon KE. 2014b. Unfolding the dimensional structure of DSM-5 personality traits in adolescence. F. Personal. In press

De Clercq B, De Fruyt F, Van Leeuwen K. 2004. A "little-five" lexically based perspective on personality disorder symptoms in adolescence. F. Personal. Disord. 18(5):479-99

De Clercq B, De Fruyt F, Van Leeuwen K, Mervielde I. 2006. The structure of maladaptive personality traits in childhood: a step toward an integrative developmental perspective for DSM-V.F. Abnorm. Psychol. 115(4):639-57

De Clercq B, De Fruyt F, Widiger TA. 2009a. Integrating a developmental perspective in dimensional models of personality disorders. Clin. Psychol. Rev. 29(2):154-62

De Clercq B, Van Leeuwen K, Van Den Noortgate W, De Bolle M, De Fruyt F. 2009b. Childhood personality pathology: dimensional stability and change. Dev. Psychopathol. 21:853-69

Decuyper M, De Pauw S, De Fruyt F, De Bolle M, De Clercq BJ. 2009. A meta-analysis of psychopathy-, antisocial PD- and FFM associations. Eur. 7. Personal. 23(7):531-65

De Fruyt F, Bartels M, Van Leeuwen KG, De Clercq B, Decuyper M, Mervielde I. 2006. Five types of personality continuity in childhood and adolescence. F. Personal. Soc. Psychol. 91(3):538-52

www.annualreviews.org • Childhood Antecedents of Personality Disorder
Provides an informative introduction to the landmark Children in the Community Study.

Describes the development of the first bottom-up constructed taxonomy of maladaptive traits in childhood.

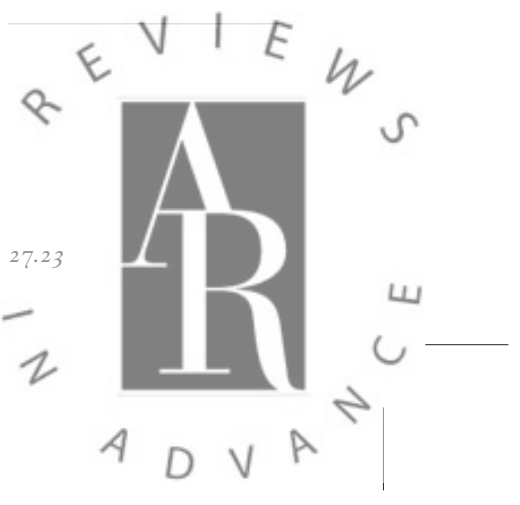


Provides a comprehensive meta-analysis looking at the stability of general and disordered personality across the life span, as well as in patient samples, taking into account measurement error.

Provides an authoritative review on what can be learned from the DSM-past for future developments.

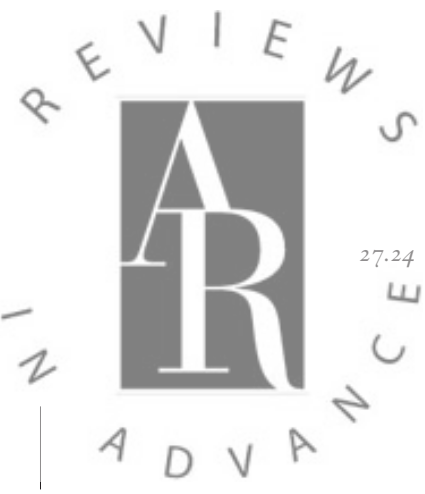

De Fruyt F, De Bolle M, McCrae RR, Terracciano A, Costa PT. 2009a. Assessing the universal structure of personality in early adolescence: the NEO-PI-R and NEO-PI-3 in 24 cultures. Assessment 16(3):30111

De Fruyt F, De Clercq B. 2012. Childhood antecedents of personality disorders. In The Oxford Handbook of Personality Disorders, ed. TA Widiger, pp. 166-85. Oxford, UK: Oxford Univ. Press

De Fruyt F, De Clercq B. 2013. Childhood antecedents of personality disorder: a five-factor model perspective. In Personality Disorders and the Five-Factor Model of Personality, ed. TA Widiger, PT Costa Jr, pp. 43-60. Washington, DC: APA

De Fruyt F, De Clercq B, De Bolle M, Wille B, Markon K, Krueger RF. 2013. General and maladaptive traits in a five-factor framework for DSM-5 in a university student sample. Assessment 20(3):295-307

De Fruyt F, De Clercq BJ, Miller J, Rolland JP, Jung SC, et al. 2009b. Assessing personality at risk in personnel selection and development. Eur. 7. Personal. 23(1):51-69

De Pauw SSW, Mervielde I, Van Leeuwen KG. 2009. How are traits related to problem behavior in preschoolers? Similarities and contrasts between temperament and personality. F. Abnorm. Child Psychol. 37(3):30925

De Raad B, Barelds DPH, Levert E, Ostendorf F, Mlacic B, et al. 2010. Only three factors of personality description are fully replicable across languages: a comparison of 14 trait taxonomies. 7. Personal. Soc. Psychol. 98(1):160-73

Dick DM. 2011. Gene-environment interaction in psychological traits and disorders. Annu. Rev. Clin. Psychol. 7:383-409

Digman JM. 1963. Principal dimensions of child personality as inferred from teachers' judgements. Child Dev. $34: 43-60$

Dishion TJ, Tipsord M. 2011. Peer contagion in child and adolescent social and emotional development. Annu. Rev. Psychol. 62:189-214

Eaton NR, Krueger RF, South SC, Simms LJ, Clark LA. 2011. Contrasting prototypes and dimensions in the classification of personality pathology: evidence that dimensions, but not prototypes, are robust. Psychol. Med. 41(6):1151-63

Ellis BJ, Boyce WT, Belsky J, Bakermans-Kranenburg MJ, van IJzendoorn MH. 2011. Differential susceptibility to the environment: an evolutionary-neurodevelopmental theory. Dev. Psychopathol. 23(1):728

Ferguson CJ. 2010. A meta-analysis of normal and disordered personality across the life span. 7. Personal. Soc. Psychol. 98:659-67

First MB, Gibbon M, Spitzer RL, Williams JBW, Benjamin LS. 1997. Structured Clinical Interview for DSM-IV Axis II Personality Disorders. Washington, DC: Am. Psychiatr. Publ.

Frances AJ, Widiger T. 2012. Psychiatric diagnosis: lessons from the DSM-IV past and cautions for the DSM-5 future. Annu. Rev. Clin. Psychol. 8:109-30

Frick PJ, Nigg JT. 2012. Current issues in the diagnosis of attention deficit hyperactivity disorder, oppositional defiant disorder, and conduct disorder. Annu. Rev. Clin. Psychol. 8:77-107

Goldberg LR. 1990. An alternative description of personality-the Big-5 factor structure. F. Personal. Soc. Psychol. 59(6):1216-29

Goldsmith HH, Campos JJ. 1982. Toward a theory of infant temperament. In The Development of Attachment and Affiliative Systems, ed. RN Emde, RJ Harmon, pp. 161-93. New York: Plenum

Goldsmith HH, Lemery KS, Essex MJ. 2004. Roles for temperament in the liability to psychopathology in childhood. In Behavior Genetic Principles: Development, Personality and Psychopathology, ed. L DiLalla, pp. 9-19. Washington, DC: APA

Gore WL, Widiger TA. 2013. The DSM-5 dimensional trait model and five-factor models of general personality. F. Abnorm. Psychol. 122:816-21

Graziano WG, Eisenberg NH. 1997. Agreeableness: a dimension of personality. In Handbook of Personality Psychology, ed. R Hogan, J Johnson, S Briggs, pp. 795-824. New York: Academic

Halverson CF, Havill VL, Deal J, Baker SR, Victor JB, et al. 2003. Personality structure as derived from parental ratings of free descriptions of children: the Inventory of Child Individual Differences. F. Personal. 71(6):995-1026

De Fruyt • De Clercq 
Herr NR, Hammen C, Brennan PA. 2008. Maternal borderline personality disorder symptoms and adolescent psychosocial functioning. F. Personal. Disord. 22(5):451-65

Hoekstra HA, Ormel J, De Fruyt F. 1996. NEO-PI-R/NEO-FFI: Big Five Persoonlijkheidsvragenlijst [NEO-PIR/NEO-FFI: Big Five Personality Inventory]. Lisse, The Neth.: Swets \& Zeitlinger

John OP, Caspi A, Robins RW, Moffitt TE, Stouthamer-Loeber M. 1994. The "little five"-exploring the nomological network of the five-factor model of personality in adolescent boys. Child Dev. 65(1):160-78

Johnson JG, Cohen P, Kasen S, Skodol AE, Hamagami F, Brook JS. 2000. Age-related change in personality disorder trait levels between early adolescence and adulthood: a community-based longitudinal investigation. Acta Psychiatr. Scand. 102:265-75

Kogan LS, Smith J, Jenkins S. 1977. Ecological validity of indicator data as predictors of survey findings. 7. Soc. Sci. Res. 1:117-32

Kohnstamm GA, Halverson CF Jr, Mervielde I, Havill VL. 1998. Parental Descriptions of Child Personality. Developmental Antecedents of the Big Five? Mahwah, NJ: Erlbaum

Konu AI, Lintonen TP, Rimpelä MK. 2002. Factors associated with schoolchildren's general subjective wellbeing. Health Educ. Res. 17:155-65

Krueger RF. 2005. Continuity of Axes I and II: toward a unified model of personality, personality disorders, and clinical disorders. F. Personal. Disord. 19(3):233-61

Krueger RF, Derringer J, Markon KE, Watson D, Skodol AE. 2012. Initial construction of a maladaptive personality trait model and inventory for DSM-5. Psychol. Med. 42(9):1879-90

Laceulle OM, Nederhof E, Karreman A, Ormel J, Van Aken MAG. 2012. Stressful events and temperament change during early and middle adolescence: the TRAILS study. Eur. F. Personal. 26(3):276-84

Lahey BB, Applegate B, Chronis AM, Jones HA, Williams SH, et al. 2008. Psychometric characteristics of a measure of emotional dispositions developed to test a developmental propensity model of conduct disorder. F. Clin. Child Adolesc. Psychol. 37(4):794-807

Lahey BB, Van Hulle CA, Singh AL, Waldman ID, Rathouz PJ. 2011. Higher-order genetic and environmental structure of prevalent forms of child and adolescent psychopathology. Arch. Gen. Psychiatry 68(2):181-89

Lenzenweger MF. 1999. Stability and change in personality disorder features: the longitudinal study of personality disorders. Arch. Gen. Psychiatry 56:1009-15

Linde JA, Stringer D, Simms LJ, Clark LA. 2013. The Schedule for Nonadaptive and Adaptive Personality for Youth (SNAP-Y): a new measure for assessing adolescent personality and personality pathology. Assessment 20(4):387-404

Livesley WJ. 1990. Dimensional Assessment of Personality Pathology—Basic Questionnaire. Vancouver: Univ. B.C. Martel MM, Goth-Owens T, Martinez-Torteya C, Nigg JT. 2010. A person-centered personality approach to heterogeneity in attention-deficit/hyperactivity disorder (ADHD). F. Abnorm. Psychol. 119(1):186-96

McCrae RR, Costa PT Jr. 1996. Toward a new generation of personality theories: theoretical contexts for the five-factor model. In The Five-Factor Model of Personality: Theoretical Perspectives, ed. JS Wiggins, pp. 51-87. New York/London: Guilford

McCrae RR, Costa PT Jr, Terracciano A, Parker WD, Mills CJ, et al. 2002. Personality trait development from age 12 to age 18: longitudinal, cross-sectional, and cross-cultural analyses. F. Personal. Soc. Psychol. 83(6):1456-68

McCrae RR, Martin TA, Costa PT Jr. 2005. Age trends and age norms for the NEO Personality Inventory-3 in adolescents and adults. Assessment 12(4):363-73

McGowan PO, Sasaki A, D’Alessio AC, Dymov S, Labonte B, et al. 2009. Epigenetic regulation of the glucocorticoid receptor in human brain associates with childhood abuse. Nat. Neurosci. 12(3):342-48

Mervielde I, Asendorpf JB. 2000. Variable-centred and person-centred approaches to childhood personality. In Advances in Personality Psychology, ed. SE Hampson, pp. 37-76. East Sussex, UK: Psychol. Press

Mervielde I, Buyst V, De Fruyt F. 1995. The validity of the Big Five as a model for teachers' ratings of individual differences among children aged 4-12 years. Personal. Individ. Differ. 18(4):525-34

Mervielde I, De Fruyt F. 1999. Construction of the Hierarchical Personality Inventory for Children (HiPIC). In Personality Psychology in Europe, Proc. 8th Eur. Conf. Personal. Psychol., ed. I Mervielde, I Deary, F De Fruyt, F Ostendorf, pp. 107-27. Tilburg, The Neth.: Tilburg Univ. Press

Mervielde I, De Fruyt F, De Clercq B. 2009. Hiërarchische Persoonlijkheidsvragenlijst voor Kinderen: Handleiding [Hierarchical Personality Inventory for Children: Manual]. Amsterdam: Hogrefe

www.annualreviews.org • Childhood Antecedents of Personality Disorder
Describes the construction of the trait model proposed in DSM-5 section III for further evaluation and research.

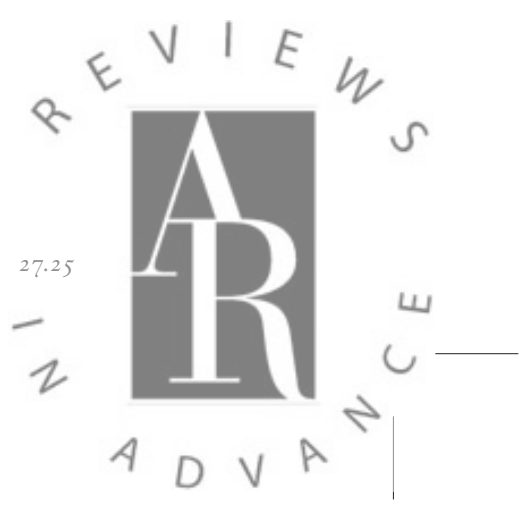


A challenging and innovative book on the temperamental substrates of behavior and psychopathology.

Reports a major meta-analysis showing how PDs are associated with FFM domain and facet traits.

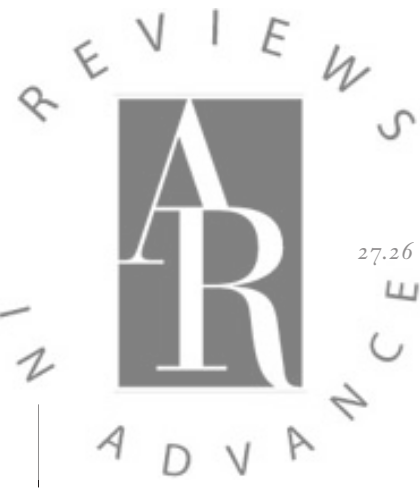

Nederhof E, Bouma EMC, Riese H, Laceulle OM, Ormel J, Oldehinkel AJ. 2010. Evidence for plasticity genotypes in a gene-gene-environment interaction: the TRAILS study. Genes Brain Bebav. 9(8):968-73

Ormel J, Bastiaansen A, Riese H, Bos EH, Servaas M, et al. 2013. The biological and psychological basis of neuroticism: current status and future directions. Neurosci. Biobehav. Rev. 37:59-72

Paris J. 2005. Neurobiological dimensional models of personality: a review of the models of Cloninger, Depue, and Siever. F. Personal. Disord. 19:156-70

Penney SR, Moretti MM. 2010. The roles of affect dysregulation and deficient affect in youth violence. Crim. Fustice Behav. 37:709-31

Raine A, Mellingen K, Liu J, Venables P, Mednick SA. 2003. Effects of environmental enrichment at ages 3-5 years on schizotypal personality and antisocial behavior at ages 17 and 23 years. Am. F. Psychiatry $160: 1627-35$

Rettew DC. 2000. Avoidant personality disorder, generalized social phobia, and shyness: putting the personality back into personality disorders. Harv. Rev. Psychiatry 8(6):283-97

Rettew DC. 2013. Child Temperament: New Thinking About the Boundary Between Traits and Illness. New York: Norton

Rothbart MK, Derryberry D. 1981. Development of individual differences in temperament. In Advances in Developmental Psychology, ed. ME Lamb, AL Brown, 1:37-86. Hillsdale, NJ: Erlbaum

Rudolph KD, Troop-Gordon W, Llewellyn N. 2013. Interactive contributions of self-regulation deficits and social motivation to psychopathology: unraveling divergent pathways to aggressive behavior and depressive symptoms. Dev. Psychopathol. 25:407-18

Rutter M. 2012. Gene-environment interdependence. Eur. F. Dev. Psychol. 9(4):391-412

Samuel DB, Hopwood CJ, Krueger RF, Thomas KM, Ruggero CJ. 2013. Comparing methods for scoring personality disorder types using maladaptive traits in DSM-5. Assessment 20(3):353-61

Samuel DB, Widiger TA. 2008. A meta-analytic review of the relationships between the five-factor model and DSM-IV-TR personality disorders: a facet level analysis. Clin. Psychol. Rev. 28(8):132642

Saulsman LM, Page AC. 2004. The five-factor model and personality disorder empirical literature: a metaanalytic review. Clin. Psychol. Rev. 23(8):1055-85

Schaeffer CM, Borduin CM. 2005. Long-term follow-up to a randomized clinical trial of multisystemic therapy with serious and violent juvenile offenders. 7. Consult. Clin. Psychol. 73:445-53

Schotte CKW, De Doncker DAM, Dmitruk D, Van Mulders I, D’Haenen H, Cosyns P. 2004. The ADPIV questionnaire: differential validity and concordance with the semi-structured interview. F. Personal. Disord. 18(4):405-19

Shiner RL. 2007. Personality disorders. In Assessment of Childhood Disorders, ed. EJ Mash, RA Barkley, pp. 781816. New York: Guilford. 4th ed.

Shiner RL. 2009. The development of personality disorders: perspectives from normal personality development in childhood and adolescence. Dev. Psychopathol. 21(3):715-34

Simms LJ, Goldberg LR, Roberts JE, Watson D, Welte J, Rotterman JH. 2011. Computerized adaptive assessment of personality disorder: introducing the CAT-PD project. F. Personal. Assess. 93(4):380-89

Skodol AE. 2012. Personality disorders in DSM-5. Annu. Rev. Clin. Psychol. 8:317-44

Skodol AE, Gunderson JG, Shea MT, McGlashan TH, Morey LC, et al. 2005. The Collaborative Longitudinal Personality Disorders Study (CLPS): overview and implications. F. Personal. Disord. 19:487-504

Skodol AE, Siever LJ, Livesley WJ, Gunderson JG, Pfohl B, Widiger TA. 2002. The borderline diagnosis II: biology, genetics, and clinical course. Biol. Psychiatry 51(12):951-63

Spitzer RL, Williams JBW. 1986. Structured Clinical Interview for DSM-III-R Personality Disorders (SCID-II). New York: NY State Psychiatr. Inst.

Stepp SD, Burke JD, Hipwell AE, Loeber R. 2012a. Trajectories of attention deficit hyperactivity disorder and oppositional defiant disorder symptoms as precursors of borderline personality disorder symptoms in adolescent girls. F. Abnorm. Child Psychol. 40:7-20

Stepp SD, Whalen DJ, Pilkonis PA, Hipwell AE, Levine MD. 2012b. Children of mothers with borderline personality disorder: identifying parenting behaviors as potential targets of intervention. Personal. Disord. Theory Res. Treat. 3:76-91

De Fruyt • De Clercq 
Stepp SD, Yu L, Miller JD, Hallquist MN, Trull TJ, Pilkonis PA. 2012c. Integrating competing dimensional models of personality: linking the SNAP, TCI, and NEO using item response theory. Personal. Disord. Theory Res. Treat. 3(2):107-26

Stoltz S, Prinzie P, De Haan A, Van Londen M, Orobio de Castro B, Dekovic M. 2013. Child personality as moderator of outcome in a school-based intervention for preventing externalising behavior. Eur. $\mathcal{F}$. Personal. 27:271-79

Tackett JL. 2010. Measurement and assessment of child and adolescent personality pathology: introduction to the special issue. F. Psychopathol. Behav. Assess. 32(4):463-66

Tackett JL, Balsis S, Oltmanns TF, Krueger RF. 2009. A unifying perspective on personality pathology across the life span: developmental considerations for the fifth edition of the Diagnostic and Statistical Manual of Mental Disorders. Dev. Psychopathol. 21(3):687-713

Tackett JL, Kushner SC, De Fruyt F, Mervielde I. 2014a. Mapping the terrain of personality traits in childhood and adolescence: associations across measures, temperament, and behavioral problems. Manuscr. submitted

Tackett JL, Lahey BB, Van Hulle C, Waldman I, Krueger RF, Rathouz PJ. 2014b. Common genetic influences on negative emotionality and a general psychopathology factor in childhood and adolescence. F. Abnorm. Psychol. In press

Tett RP, Burnett DD. 2003. A personality trait-based interactionist model of job performance. F. Appl. Psychol. 88(3):500-17

Thomas A, Chess S. 1977. Temperament and Development. New York: Brunner/Mazel

Tromp NB, Koot HM. 2008. Dimensions of personality pathology in adolescents: psychometric properties of the DAPP-BQ-A. 7. Personal. Disord. 22(6):623-38

Tromp NB, Koot HM. 2009. Dimensions of personality pathology in adolescents: relations to DSM-IV personality disorder symptoms. F. Personal. Disord. 23(5):514-27

Trull TJ, Vergés A, Wood PK, Sher KJ. 2013. The structure of DSM-IV-TR personality disorder diagnoses in NESARC: a reanalysis. F. Personal. Disord. 27:727-34

Tyrer P. 2012. DSM: a classification of personality disorders that has had its day. Clin. Psychol. Psychother. 19:372-74

Tyrer P. 2013. The classification of personality disorders in ICD-11: implications for forensic psychiatry. Crim. Behav. Mental Health 23:1-5

Van Leeuwen K, De Fruyt F, Mervielde I. 2004a. A longitudinal study of the utility of the resilient, overcontrolled, and undercontrolled personality types as predictors of children's and adolescents' problem behaviour. Int. F. Behav. Dev. 28(3):210-20

Van Leeuwen KG, Mervielde I, Braet C, Bosmans G. 2004b. Child personality and parental behavior as moderators of problem behavior: variable- and person-centered approaches. Dev. Psychol. 40(6):1028-46

Verbeke L, De Clercq B. 2014. Integrating Childhood Oddity Traits in a Dimensional Model for Personality Pathology Precursors. Manuscr. submitted

Warner MB, Morey LC, Finch JF, Gunderson JG, Skodol AE, et al. 2004. The longitudinal relationship of personality traits and disorders. F. Abnorm. Psychol. 113(2):217-27

Widiger TA, Clark LA. 2000. Toward DSM-V and the classification of psychopathology. Psychol. Bull. 126(6):946-63

Widiger TA, De Clercq B, De Fruyt F. 2009a. Childhood antecedents of personality disorder: an alternative perspective. Dev. Psychopathol. 21(3):771-91

Widiger TA, Livesley WJ, Clark LA. 2009b. An integrative dimensional classification of personality disorder. Psychol. Assess. 21(3):243-55

Widiger TA, Mullins-Sweatt SN. 2009. Five-factor model of personality disorder: a proposal for DSM-V. Annu. Rev. Clin. Psychol. 5:197-220

Widiger TA, Samuel DB. 2005. Diagnostic categories or dimensions? A question for the Diagnostic and Statistical Manual of Mental Disorders-fifth edition. 7. Abnorm. Psychol. 114(4):494-504

Widiger TA, Trull TJ, Clarkin JF, Sanderson C, Costa PT. 2002. A description of the DSM-IV personality disorders with the five-factor model of personality. In Personality Disorders and the Five-Factor Model of Personality, ed. PT Costa, TA Widiger, pp. 89-99. Washington, DC: APA. 2nd ed.

www.annualreviews.org • Childhood Antecedents of Personality Disorder
Illustrates how overlap among different personality models can be examined and integrated to optimize personality assessment.

An editorial that introduces a special issue compiling a set of challenging papers on precursors and pathways to PD in preadulthood.

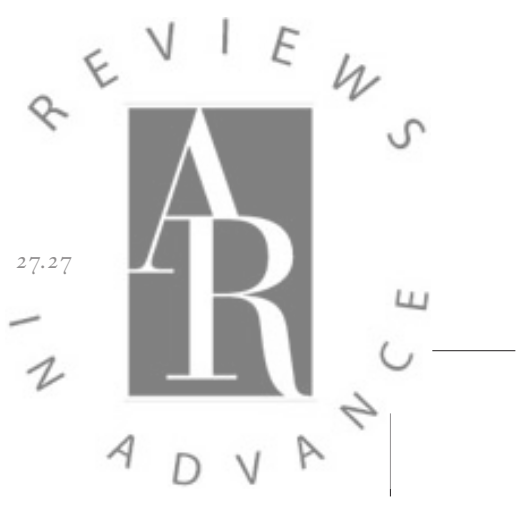


Wilkinson PO, Trzaskowski M, Haworth CMA, Eley TC. 2013. The role of gene-environment correlations and interactions in middle childhood depressive symptoms. Dev. Psychopathol. 25(1):93-104

Wille B, De Fruyt F, De Clercq B. 2013. Expanding and reconceptualizing aberrant personality at work: validity of five-factor model aberrant personality tendencies to predict career outcomes. Pers. Psychol. 66(1):173-223

World Health Organ. (WHO). 1994. The International Classification of Diseases. Geneva: WHO

World Health Organ. (WHO). 2010. The International Classification of Diseases. Geneva: WHO

Zanarini MC, Frankenburg FR, Hennen J, Reich DB, Silk KR. 2005. The McLean Study of Adult Development (MSAD): overview and implications of the first six years of prospective follow-up. F. Personal. Disord. 19:505-23

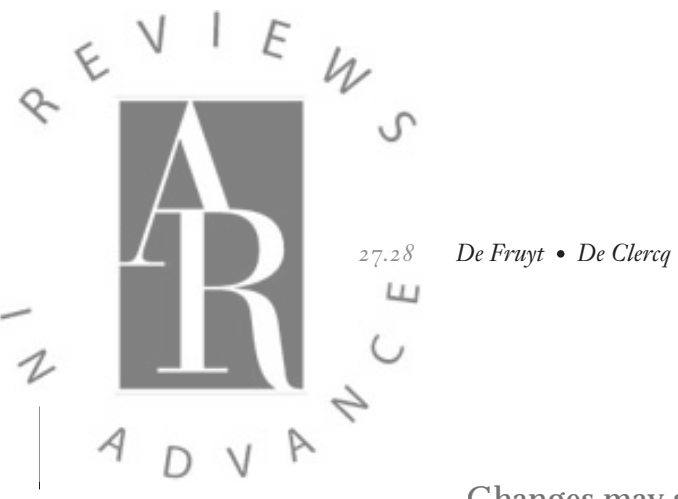

